NIST

PUBLICATIONS

\title{
Field Modeling of Room Fires
}

William D. Davis

Glenn P. Forney

John H. Klote

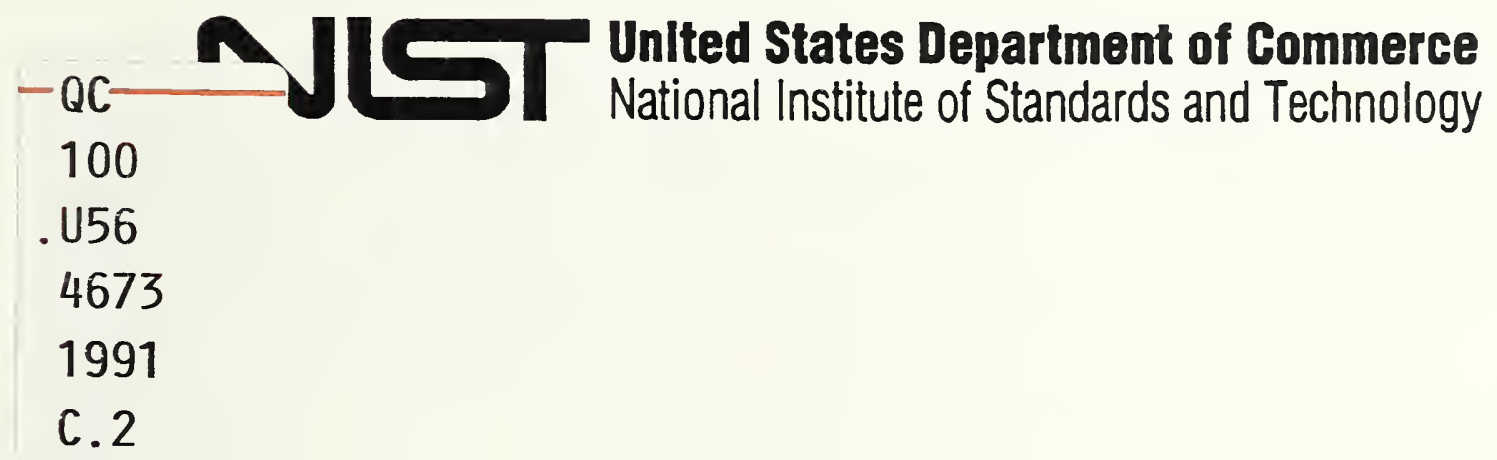





\section{Field Modeling of Room Fires}

William D. Davis

Glenn P. Forney

John H. Klote

No vember 1991

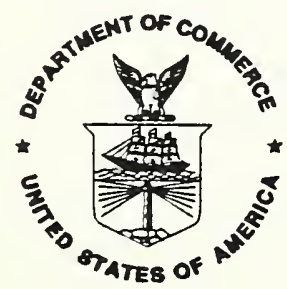

U.S. Department of Commerce

Robert A. Mosbacher, Secretary

National Institute of Standards and Technology

John W. Lyons, Director

Building and Fire Research Laboratory

Gaithersburg, MD 20899 



\section{Contents}

1 Introduction 1

1.1 The Field Model . . . . . . . . . . . . . . . . . . . 2

1.1.1 Pre-Processing Software: GRIDGEN . . . . . . . . . 4

1.1.2 Processing Software: FLOW3D . . . . . . . . . . . . 4

1.1.3 Post-Processing Software: OUTPROC, TRAN and SURF3D 4

1.1.4 General Field Model Setup Information . . . . . . . . 5

1.2 Field Model - Zone Model Comparisons . . . . . . . . . . . . 6

2 One Room Experiment 7

2.1 Experimental and Field Model Setup ... . . . . . . . . . 7

2.2 Comparison of Experimental, Zone Modeling and Field Modeling

Results . . . . . . . . . . . . . . . . . . . . 10

2.3 Computational Accuracy . . . . . . . . . . . . . . 16

3 Three Room Experiment 20

3.1 Experimental and Field Model Setup . . . . . . . . . . . 20

3.2 Comparison of Experimental and Numerical Results . . . . . . . 23

4 Summary 26

References $\quad 28$

A Field Model Command Files $\quad 30$

A.1 One-Room Command Files . . . . . . . . . . . . . . 30

A.1.1 Field Model Command File for the One-Room Experiment 30

A.1.2 OUTPROC Command File for the One-Room Experiment 32

A.2 Three-Room Field Model Command File . . . . . . . . . . . 35

B Field Model Subroutines 38

B.1 TRAN Subroutines . . . . . . . . . . . . . . . 38

B.2 Outlet Subroutines . . . . . . . . . . . . . . . . . 38

B.3 Heat Source Subroutine . . . . . . . . . . . . . . . . 39

B.4 Fusible Link Subroutine . . . . . . . . . . . . . . . . . . . 39

B.5 Machine Dependent Parameter Subroutine . . . . . . . . . . 39

$\begin{array}{ll}\text { C Boundary Conditions } & 39\end{array}$ 


\section{List of Figures}

1 FLOW3D Program and Data File Dependency Diagram . . . . . 3

2 Setup for the One-Room Experiment . . . . . . . . . . . . 9

3 Ceiling Jet Temperatures at 100 Seconds . . . . . . . . . . . 10

4 Ceiling Jet Temperatures at 150 Seconds . . . . . . . . . . . . 11

5 Fusible Link Temperatures at 100 Seconds . . . . . . . . . . . 11

6 Fusible Link Temperatures at 150 Seconds . . . . . . . . . . . . 12

7 Temperature Contour Plot . . . . . . . . . . . . . . . . . 12

8 Velocity Vector Plot . . . . . . . . . . . . . . . . . 13

9 Horizontal Vent Velocities at 200 Seconds . . . . . . . . . . . 14

10 Vertical Vent Velocities at 200 Seconds . . . . . . . . . . . . . . 15

11 One and Two Room Temperature Profile in the Vent . . . . . . 15

12 Horizontal Velocity Profiles in the Vent ... . . . . . . . . 16

13 Zone and Field Model Temperature Profiles in the Vent ..... 17

14 Inner Pressure Iteration Impact on Computer Time and Mass Residuals ....................... 18

15 Outer Iteration Impact on Computer Time and Mass Residuals . 19

16 Time Step-Size Impact on Computer Time and Mass Residuals . 19

17 Three Room Experimental Layout and Thermocouple Configuration . . . . . . . . . . . . . . . . 21

18 Temperature Profiles for Thermocouple Tree 1 at 500 Seconds . . 23

19 Temperature Profiles for Thermocouple Tree 2 at 500 Seconds . . 24

20 Temperature Profiles for Thermocouple Tree 3 at 500 Seconds . . 24

21 Temperature Profiles for Thermocouple Tree 5 at 500 Seconds . . 25

22 Temperature Profiles for Thermocouple Tree 8 at 500 Seconds . . 25

\section{List of Tables}

1 Room Dimensions for the One-Room Experiment . . . . . . . . 8

2 Room Dimensions for the Three-Room Experiment . . . . . . . . 20 


\title{
Field Modeling of Room Fires
}

\author{
William D. Davis Glenn P. Forney John H. Klote
}

\begin{abstract}
The application of the Harwell field model FLOW3D to model compartment fires is investigated. Two experiments are chosen to model numerically. The first experiment is a single room fire where the vertical structure of the ceiling jet produced by the fire is measured and the temperature response of simulated fusible links to the ceiling jet is available. The second experiment consists of three rooms with a fire in one of the rooms. Temperature measurements using thermocouples are available in each of the three rooms as well as in the corridors connecting the rooms. These two experiments provide an opportunity to investigate both two and three dimensional field modeling of fires. It is found that the numerical results using the field model are in reasonable agreement with the experimental data. FLOW3D has been enhanced by the addition of a simple fusible link algorithm previously used in the zone fire model LAVENT. This algorithm used in conjunction with the field model produces good agreement with the measured fusible link temperatures found in the single room experiment.
\end{abstract}

\section{Introduction}

The purpose of this report is to describe the use of the Harwell field model, FLOW3D, for modeling compartment fires[1]. This model was applied by Harwell to simulate the fire at the King's Cross underground station [2]. In that application the field model, surprisingly, predicted that the fire would lay down (instead of rising straight up) in the trench formed by the walls and steps of the wooden escalator. Although this prediction was met at first with much skepticism, it was shown by both the model and by experiment that the behavior of the fire was due to two related phenomena. The first effect also known as the 'Coanda' effect was the preferential entrainment of air into the plume from below. The second effect was the high wind speeds $(14.5 \mathrm{~m} / \mathrm{s}$ predicted by the model [2]) along the base of the escalator. These two phenomena together have been referred to as the "trench effect". Similar insight may be attained by applying tools such as this to other fire scenarios that have complex geometries or flow fields. But first, further comparisons of the model's predictions with 
laboratory fire experiments, which are both controlled and well instrumented, are necessary to gain confidence in the predictive capability of the model.

The experiments described in this report serve as an initial basis for verifying the application of FLOW3D for the analysis of compartment fires. The comparisons between the numerical simulations and the experimental results serve only as a preliminary verification of this field model since radiation calculations were not included in the simulation and the fires were modeled using experimentally measured heat release rates rather than the available combustion models.

Both two and three dimensional approaches to modeling fire and smoke flow were investigated. Two experiments were chosen to compare with the field model. The first experiment [3] was selected because the structure of the ceiling jet was measured in the fire room. The flow fields could be approximated using a two dimensional grid since the experiment consisted of a single room with a wide door. The numerical grid was chosen fine enough to resolve the ceiling jet structure. The experiment also had a series of simulated fusible links located at a variety of distances from the ceiling which provided a basis for comparing a simple model of fusible link heating with experimental data.

The second experiment [4] was chosen because its instrumentation and geometry provided data to illustrate three dimensional variations in the flow field. It was a three room experiment that had been used earlier to measure the calculation accuracy of the zone fire model FAST [5]. Here, the purpose was to investigate the effect of using a coarse grid in a field modeling calculation. Unlike the first experiment, no effort was made to resolve the ceiling jet and fusible links were not included in the calculation. The ability to use a coarse grid in modeling a fire experiment is important due to the limitation of computer speed which places a practical limit on the number of nodes used in a grid, particularly for a three dimensional calculation.

\subsection{The Field Model}

The fire experiments discussed in this report were simulated using release 2.3.2 of FLOW3D [1]. This model has been developed over a period of roughly a decade at Harwell Laboratories. The field model solves the three dimensional form of the equations for conservation of mass, momentum, and energy and the $k-\epsilon$ model is used to model turbulence. The required physical parameters for these equations include the fluid density, pressure, specific heat at constant pressure, acceleration of gravity, thermal conductivity and molecular viscosity. The structure of the field modeling computer package includes pre-processing and post-processing software as well as the field model itself. The interaction between these three portions of this package and the files they both produce and require is illustrated in figure 1. 


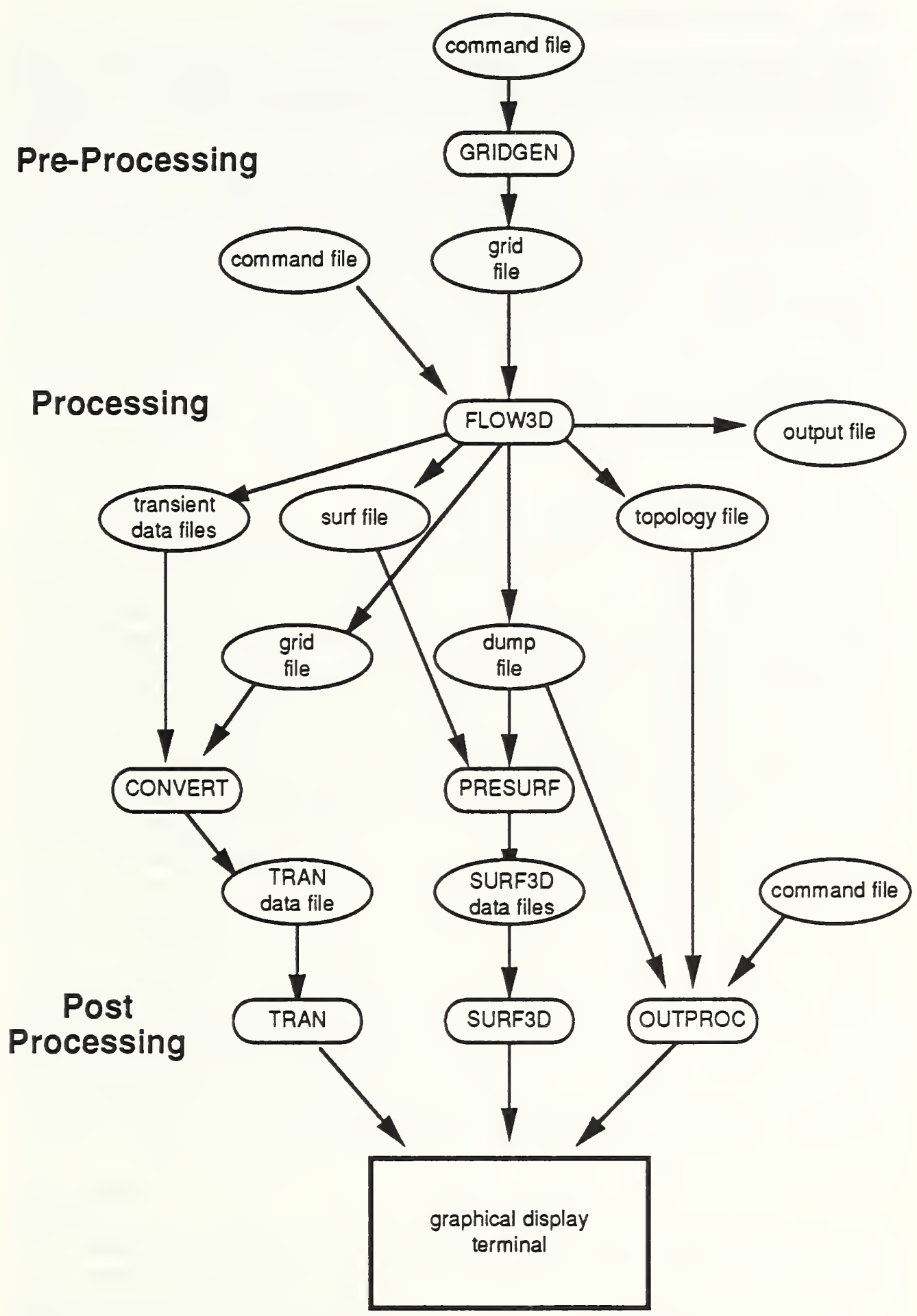

Figure 1: FLOW3D Program and Data File Dependency Diagram 


\subsubsection{Pre-Processing Software: GRIDGEN}

The pre-processing software consists of a numerical grid generation package named GRIDGEN which is used to generate body-fitted coordinates. This package was not used to generate a grid for the experiments modeled in this report since the command file used to run the field model has an option which lets the user create simple grids. This facility was more than adequate to create the simple grids used for these experiments. Complex grids must be generated using the numerical grid generator. The numerical grid generator uses a free format input file which allows the user to define the grid generation parameters using keywords. Special curves may be generated by using a FORTRAN program to generate the necessary node pattern which is then used by the grid generator to construct the required grid.

GRIDGEN creates a file named grid.data that is used by the field model to determine the location of the grid points.

\subsubsection{Processing Software: FLOW3D}

To use the field model, a free-form command file must be created which uses keywords to set the program options. Command files used for modeling both experiments are given in appendix $\mathrm{A}$. In addition to the command file, flexibility in setting program options is provided by the "FORTRAN frontend". This frontend consists of a series of FORTRAN subroutines which the user may modify to change physical parameters, add physics, modify initializations and boundary conditions, or change the format of the program output. The subroutines are re-compiled and re-loaded to form a new executable ${ }^{1}$ each time the field model is run giving the user the flexibility to customize its use. The fusible link activation algorithm was added via the FORTRAN frontend. The names and a brief description of each subroutine used in the FORTRAN frontend for both experiments are given in appendix B.

The field model produces several output files designated: dump, out, srf and topl. The dump file contains the simulation results in a binary format. The out file is examined by the user to determine whether the run was successful, ie whether mass residuals were sufficiently small. The srf file contains information used by SURF3D. The topl file contains topology information describing grid connections. If the grid was generated by the field model then it creates a file named grid.data containing grid point locations. These files (except for the out file) are used by the post-processing software described next.

\subsubsection{Post-Processing Software: OUTPROC, TRAN and SURF3D}

The post-processing software includes three output graphics programs: OUTPROC, TRAN, and SURF3D. The first program, OUTPROC, produces contour

\footnotetext{
${ }^{1}$ An executable is a file containing machine language instructions executed by the computer.
} 
plots, velocity vector plots, and particle tracks in arbitrary planes throughout the computational space. OUTPROC uses a free format input file which allows the user to define the characteristics of the generated plots using keywords. An example of the input file is given in appendix A for the two dimensional calculation.

The second output graphics program, TRAN, provides a two dimensional animation of the time evolution of a designated variable on the grid. Each node point on the grid is given a color representing the magnitude of the variable at that node. The program displays the variable values at each timestep.

The subroutines necessary to generate a TRAN file are listed in appendix B. The files produced by these subroutines are T.data, U.data, P.data etc for temperature, velocity in the $x$ direction, pressure. A file may be produced for each of the solution variables. Up to four variables may be simultaneously tracked using this software with the choice of variables specified within the TRAN subroutines. There is no user interface for the TRAN files, hence any modification to the output must be done by the user directly to the TRAN files. Before TRAN is run, a program called CONVERT is used to convert files produced by the field model (T.data $e t c$ ) into a file named trans.data. TRAN uses this file to produce an animated display for one of the solution variables. At present, TRAN can only be used for two dimensional calculations.

The third output graphics program, SURF3D, provides a three dimensional visualization of the surface boundaries (hence the name SURF3D) at one particular time for the grid used in the calculation. Several variables such as temperature or pressure may be displayed on the grid boundaries using a color representation for the variable's magnitude. The grid may be expanded, rotated, or translated and the user has the option to move within the grid boundaries to observe the internal structure of the grid surfaces. Before SURF3D is run, a program named PRESURF is used to convert files generated by the field model into a file used by SURF3D to generate the three dimensional display.

\subsubsection{General Field Model Setup Information}

The physical setup for each simulation was as follows. It was assumed that the fluid was air and that it was fully compressible. Turbulence was modeled using the $k-\epsilon$ model and included the default treatment of the boundary layer at the walls. The walls were assumed to be adiabatic except in one three dimensional calculation where heat conduction in the ceiling was included. Radiation effects were not included in the calculation except to reduce the experimental heat release rates by thirty-five percent to simulate radiation loss to the walls in the fire room.

A uniform grid was used to model each experiment. All terms in the equations except for the advection terms were discretized in space using secondorder centered differencing. For the advection terms, a number of discretization schemes were available. For this work, the upwind differencing scheme was used. 
The equations were advanced in time using a fully implicit backward difference procedure.

\subsection{Field Model - Zone Model Comparisons}

While this report is primarily concerned with field modeling, it is important to describe what a zone model is in relation to a field model since comparisons with zone model calculations will be made. As mentioned earlier, a field model solves a basic set of equations for conservation of mass, momentum, and energy on a user defined grid with the coarseness of the grid determining the physical scale lengths which can be modeled. The mass, enthalpy, flow speeds, turbulent energy etc are calculated for each cell or control volume in the grid. Techniques for modeling physical phenomena whose natural scale sizes are smaller than the grid size are used in both field and zone modeling. Models using these techniques are sometimes called sub-grid models. Plume and vent flow models are examples of this in zone models and turbulence models are examples of this in field models.

A zone model typically models an enclosure by dividing the volume of the enclosure into two layers or zones, designated the upper and lower layer. A field model divides the enclosure into many control volumes. As with field models, the temperature and density are assumed to be uniform throughout the control volume (a layer in the zone modeling case, an arbitrary grid cell in the field modeling case) at a given time. The conservation equations for mass and energy are solved for each layer. The conservation of momentum equation is usually neglected in a zone model.

Perhaps the most notable difference between a field and a zone model (besides the number of control volumes used) is the method used to model the exchange of mass and enthalpy between control volumes. A field model solves for these flows directly using the conservation laws while a zone model uses various sub-grid models (plume and vent flow for example) to model the transfer of mass and enthalpy from the fire to the layers, the entrainment of lower layer gas into the upper layer and the exchange of mass and enthalpy between connected spaces through vents etc. Transient effects, such as the time required to establish the plume or an upper layer, are usually ignored in zone models.

A zone model typically neglects the hydrostatic terms in the equation of state (the ideal gas law) which relates density, temperature and pressure since the contribution of the hydrostatic term is small. However, these terms are not neglected when calculating vent flows. These assumptions concerning hydrostatic terms are discussed in [6].

The effect of gas flow in either layer is ignored with the exception that some zone models contain a set of ceiling jet equations which represent the flow of the hot plume gases across the ceiling. Transient effects of setting up the ceiling jet are ignored in these models.

The flow of the layer gases through vents to other enclosures is calculated 
using Bernoulli's equation with a vent coefficient where the hydrostatic pressure difference across the vent as a function of height is obtained from the layer interface height and the gas density in each layer. The inflowing or outflowing mass and enthalpy are then placed in one of the layers depending on the relative temperature of the flowing gas and the layers.

The pressure field in a field model is calculated at each grid cell from the conservation equations. The pressure field in a zone model is derived from a calculated reference pressure (usually the pressure at the base of the lower layer), the layer interface height and densities of both layers. Due to neglecting the momentum equation, the pressure at a given height in a zone model is constant. This need not be true in a field model. As a result, a field model can model regimes with complex flow patterns whereas a zone model cannot.

As mass and enthalpy are added to or subtracted from the upper and lower layers in a zone model, the interface height of the two layers is adjusted to maintain pressure balance between the layers.

Examples of zone models which contain fairly sophisticated physics include FAST [5], FIRST [7], and LAVENT [8]. Zone models are most useful when the fire room and adjacent rooms have a geometry that is a simple rectangular parallelepiped and the flows introduced into the rooms by the fire are not complicated. Field models will allow the simulation of more complicated geometries and can be used in cases where the flow fields are complicated. Zone models require much less computer time to simulate a fire than field models. Hence zone models are useful for simulating fire scenarios consisting of relatively simple flow fields and geometry. Use of a field model may be required if the fire simulation requires either physics or geometries that zone models can't emulate.

\section{One Room Experiment}

\subsection{Experimental and Field Model Setup}

The one-room experiment described in [3] was chosen to compare with the field model for two reasons. First, with the fire located at the back of the room and with the door being both wide and in the front of the room, the experiment could be satisfactorily modeled in two dimensions. Second, the experiment measured the ceiling jet temperature and velocity profiles beneath the ceiling and since the room could be modeled using two dimensions a fine grid could be used to resolve the ceiling jet. The room dimensions are given in table 1.

This calculation could also be used to test the capability of the outlet boundary condition used by the field model to approximate the flow through an outlet. The assumptions made and equations used for the outlet boundary condition are given in appendix $\mathrm{C}$. Two runs were made, one with the fire room connected directly to the outside through an outlet whose size was equal to the height of the door and a second where a second room of size equal to the first was used 
Table 1: Room Dimensions for the One-Room Experiment

\begin{tabular}{ll}
\hline Location & Dimension $(\mathrm{m})$ \\
\hline Room & $2.44 \mathrm{~W} \times 3.66 \mathrm{~L} \times 2.44 \mathrm{H}$ \\
Room doorway & $.76 \mathrm{~W} \times 2.03 \mathrm{H}$ \\
\hline
\end{tabular}

in order to move the outlet boundary a substantial distance away from the fire room. The outlet boundary for the two room situation was on the far side of the second room and extended the entire vertical height of the wall. The door to the fire room then opened into the second room and was modeled using internal solid nodes to approximate the transom depth of the door. The second room was added to avoid modeling the door flow using a mathematical boundary condition.

Near the center of the room, a "tree" of 20 mil diameter chromel-alumel, bare-bead thermocouples located at the ceiling and at $0.152 \mathrm{~m}$ intervals below the ceiling were used to obtain the temperature in the enclosure as a function of height. Also near the center of the enclosure, a series of simulated sprinkler link disks, each having an $\mathrm{RTI}^{2}$ of $25.7(\mathrm{~ms})^{.5}$, diameter of $0.0095 \mathrm{~m}$, and thickness of $0.00079 \mathrm{~m}$ were positioned at $0.01,0.05,0.17,0.22$, and $0.33 \mathrm{~m}$ below the ceiling. It should be noted that reference [3] reports an RTI of $25(\mathrm{~ms})^{.5}$ for the sprinkler link disks but after rechecking the data, the RTI of the disks ranged from 25.5 to $25.8(\mathrm{~ms})^{.5}$ [9]. The total heat release of the combustibles as a function of time was deduced from oxygen consumption calorimetry measurements in a collection head outside the door.

Three different heat release rate curves [10] have been used to describe the fire which was a waste-paper basket initiated office furniture fire in one corner of the room. The linear heat release curve was used based on a successful simulation of the fire using the zone computer model LAVENT [10]. The fire volume was estimated using the heat release rate for a fully involved fire of wood pallets [11]. The volume of the fire was kept constant throughout the simulation but the heat release rate per cell was varied to mimic the total heat release of the fire.

It was assumed that $35 \%$ of the heat release was lost to radiation to the walls. Since the walls were considered adiabatic, that meant that only $65 \%$ of the heat release rate went directly to heating the gas. This ratio was kept constant throughout the simulation of the fire.

\footnotetext{
${ }^{2}$ Response time index
} 


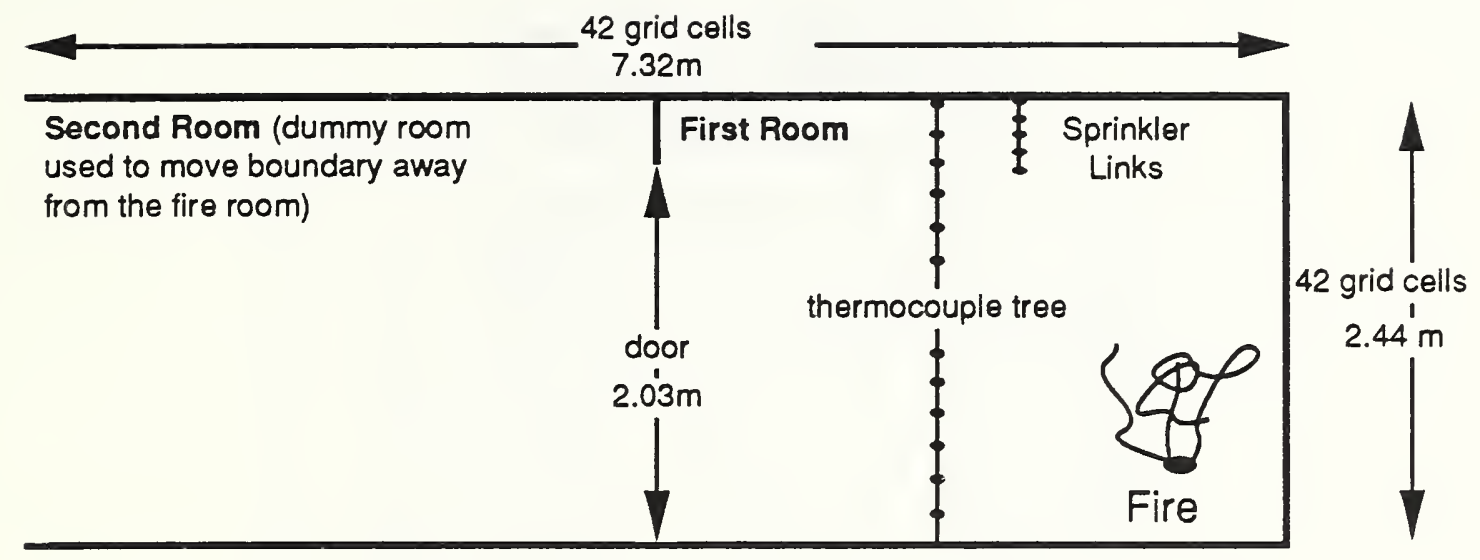

Figure 2: Setup for the One-Room Experiment

The fusible links were simulated using the simplified model of Heskestad and Smith [12]. Here, the heating of the links requires the calculation of both the flow velocity and temperature at the link location. The equation used to compute the link heating is given by

$$
\frac{d T_{1}}{d t}=\frac{\left(T-T_{1}\right) \sqrt{V}}{R T I}
$$

where $T_{1}$ is the link temperature, $T$ is the gas temperature, $V$ is the gas velocity, and $R T I$ is the response time index of the link. This model neglects the effects of radiation to the links or conduction from the links to the ceiling.

Since the fusible links were located in the center of the room, the diagonal distance from the fire center to the link position was used to model the flow distance. No effort was made to model the links near the door because of the expected three dimensional distortion of the flow field near at the door.

The experiment was modeled using a grid of $42 \times 42$ in the $x y$ plane with the $y$ dimension oriented vertically upward (see figure 2 ). This grid actually models two rooms of equal size with the fire located on the far right section of the first room and the vent occupying the entire wall of the left side of the second room. The additional room was added to eliminate the observed influence that the vent boundary conditions introduced into the calculations when a grid of $22 \times 42$ was used to simulate the experiment. These boundary effects will be discussed later in the report.

Heat conduction to the ceiling was ignored. This latter approximation was reasonable since the walls were made of marinite which is a good insulator. The heat flow through the walls during the 200 seconds of the experiment was therefore of marginal importance. Radiation to the walls and the gas was also ignored as mentioned earlier. 


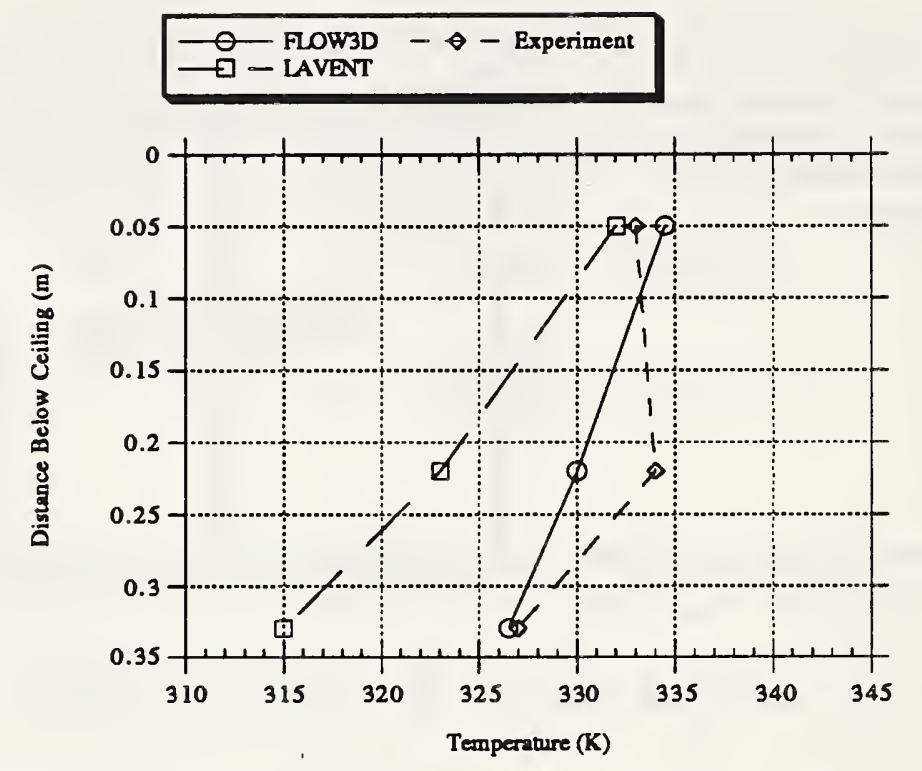

Figure 3: Ceiling Jet Temperatures at 100 Seconds

The problem was run using a timestep of .5 seconds. Larger timesteps produced poor convergence for the solver with resulting large residuals. Details of the command file are given in appendix $\mathrm{A}$.

\subsection{Comparison of Experimental, Zone Modeling and Field Modeling Results}

The ceiling jet temperatures predicted by FLOW3D and LAVENT are compared with the experimental values as shown in figure 3 and 4 . As can be observed, both the field and zone models give a good representation of the temperature of the jet at 100 and 150 seconds. A comparison of the fusible link temperatures as calculated by these two programs versus experiment is given in figures 5 and 6 for 100 and 150 seconds. Again, both models provide a good representation of the fusible link heating. It should be noted that both programs use the same physical model for fusible link heating. However, the ceiling jet calculation in LAVENT is modeled using a zone model approximation [13].

The zone model calculates an average layer height which is uniform over the entire room. The field model on the other hand calculates the flow field dynamics and hence the predicted hot smoke layer depth varies from one place in the room to another. In particular, it is pulled upward and entrained in the vicinity of the plume as shown in the temperature contour plot in figure 7. Part of the hot smoke layer is also deflected by the top of the door and part of the deflected layer is directed back toward the plume. This flow of 


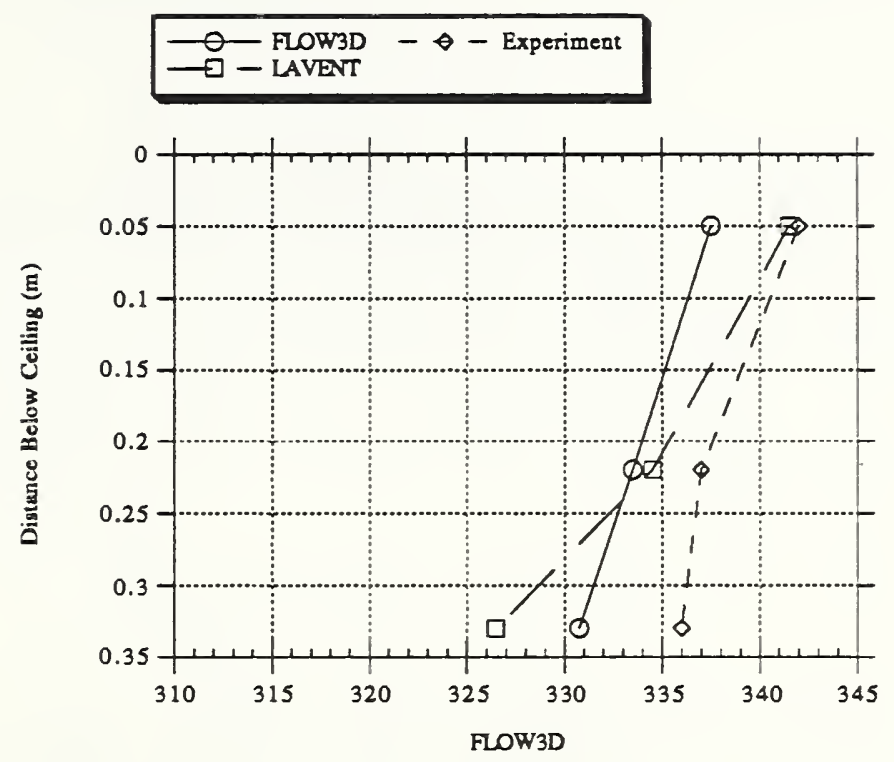

Figure 4: Ceiling Jet Temperatures at 150 Seconds

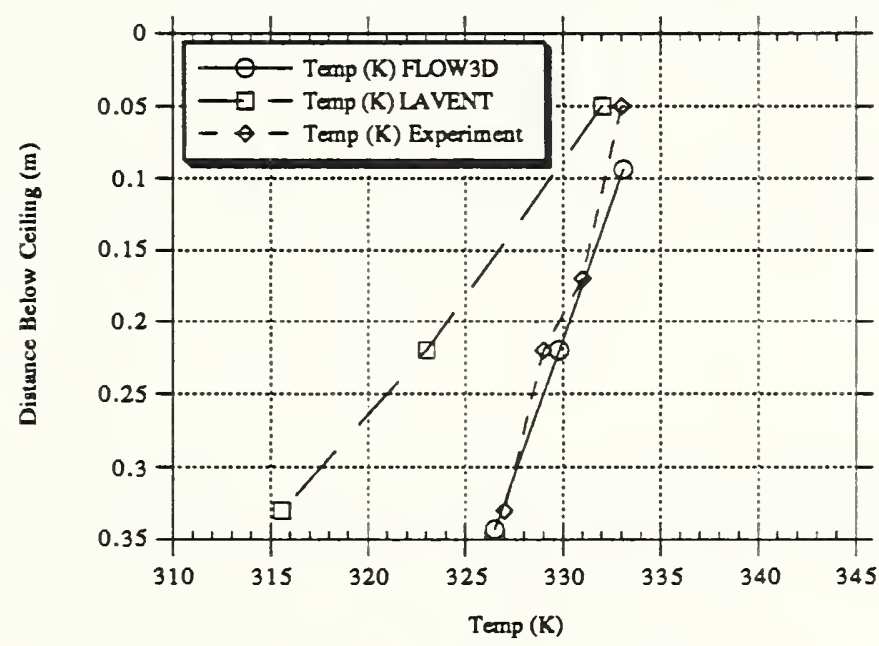

Figure 5: Fusible Link Temperatures at 100 Seconds 


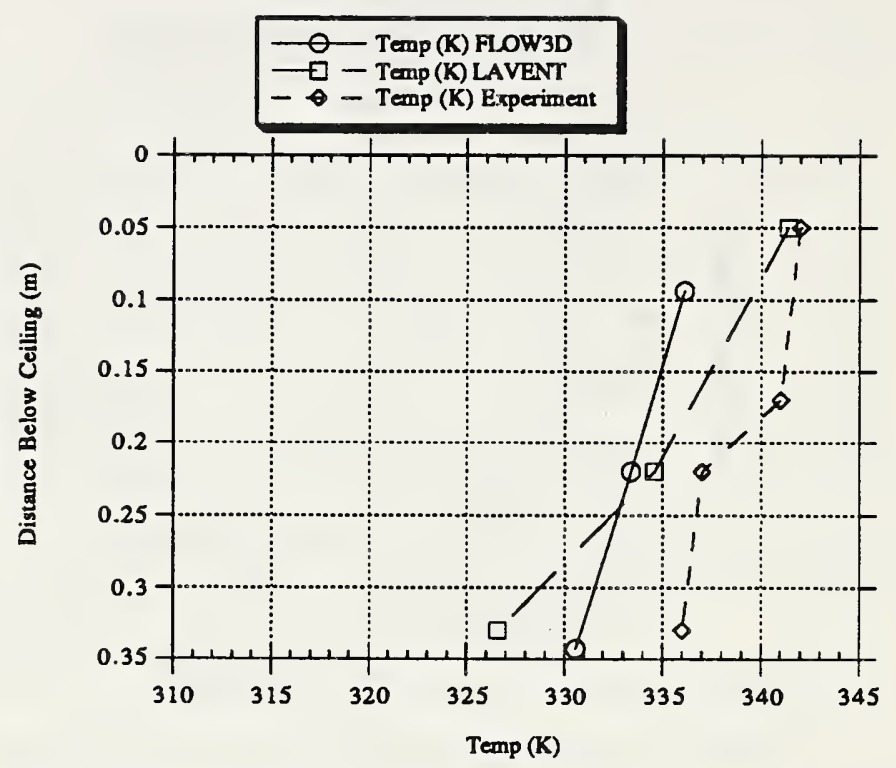

Figure 6: Fusible Link Temperatures at 150 Seconds

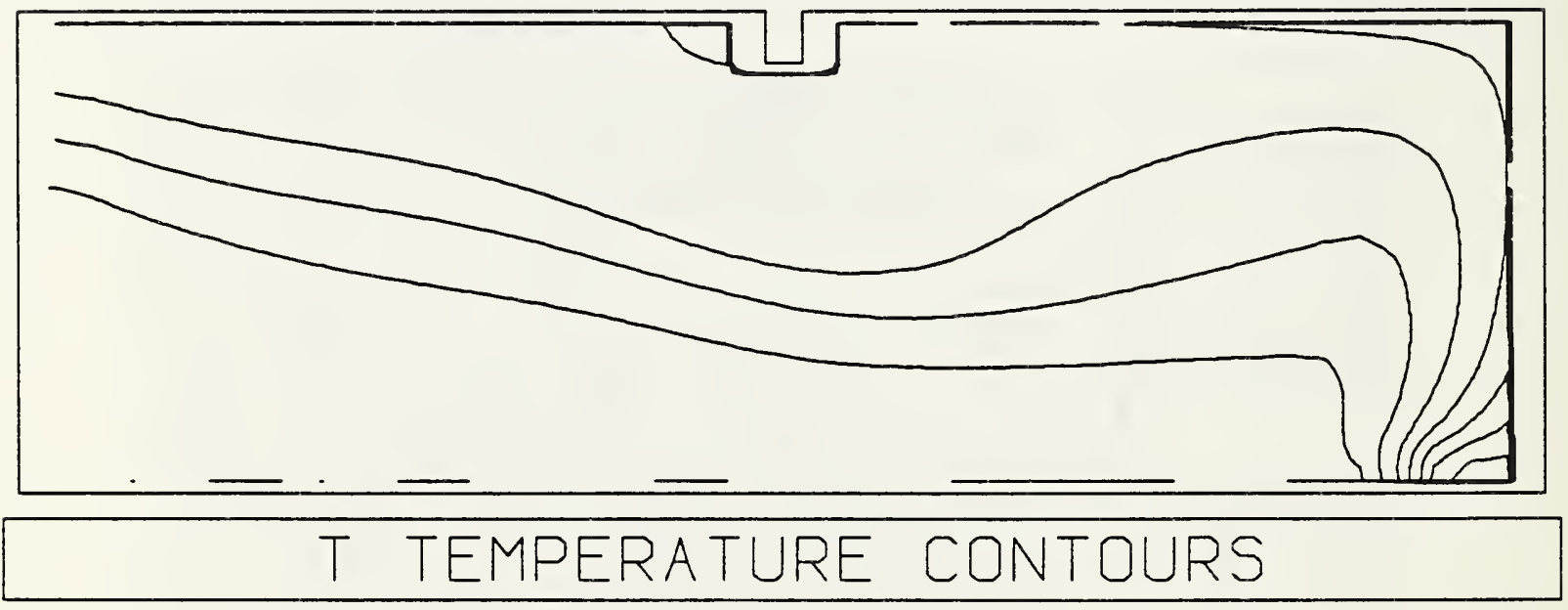

Figure 7: Temperature Contour Plot 


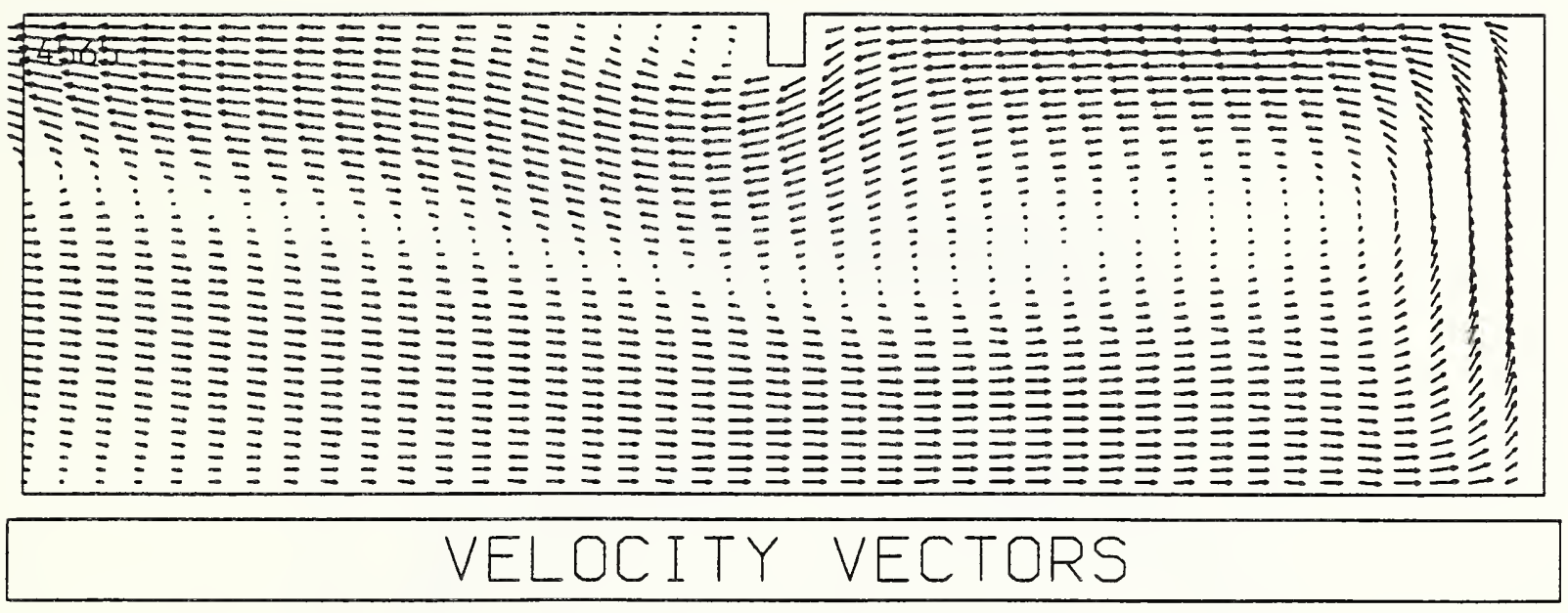

Figure 8: Velocity Vector Plot

the hot smoke gases back toward the plume is best observed using the output package "TRAN" which provides a time dependent view of the development of the gas temperature during the computation. The time independent plot of the velocity flow shown in figure 8 does not show the flow back toward the plume in a convincing manner. The arrow size in figure 8 scales with the flow velocity with the larger arrows representing greater speeds. The direction that the arrow points gives the direction of the vector flow. The mixing of the hot outflowing gas with the cool inflowing gas is a feature which is only modeled in the most sophisticated of the zone models.

The effect of the boundary condition was studied by comparing the following two numerical experiments. First, the door was modeled using the boundary condition in a one room simulation of the experiment. Second, the door was modeled using a solid grid to represent the door soffit with the boundary moved to the far end of a second room. The values for the horizontal and vertical flow velocity along the door at the grid points just inside the door were then compared for the two calculations. A plot of the horizontal and vertical flow velocities along the door for the grid just inside the door is given for the one and two room calculations (figures 9 and 10) at 200 seconds. Grid number 2 represents the control volume just above the floor with the top of the door beginning at grid number 36 . As can be seen, there are some small differences in the $x$ and $y$ velocity profiles with the $x$ flow velocities showing the largest deviations between the two methods of modeling the door. The largest contrast between the two cases can be shown if a plot of temperature, figure 11, along the grid just inside the door is examined. The outlet boundary condition (one room calculation) ignores any heating of inflowing gas by mixing with the outflowing gas and brings in the gas at the boundary reference temperature. The net result is that the temperature of the inflowing gas is underestimated using the outlet 


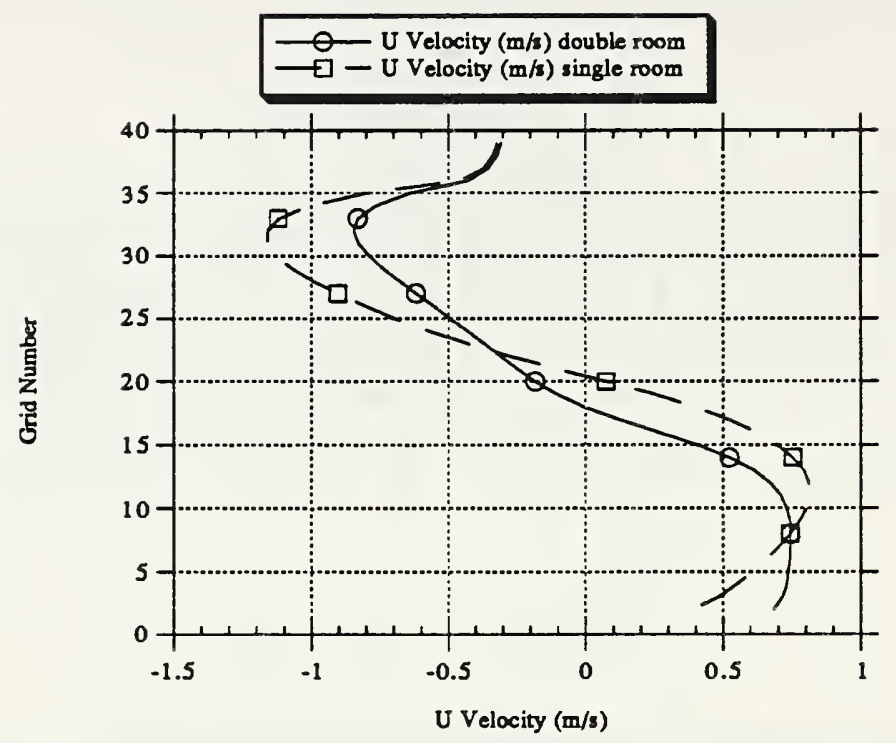

Figure 9: Horizontal Vent Velocities at 200 Seconds

boundary condition which then leads to a lower room temperature for the fire. The outlet boundary condition should only be used far from the fire source where temperatures are low and heating from the mixing of gas at the outlet would be unimportant to the overall fire simulation.

The numerical results also allow a comparison of the zone model approximation for the vent flows with that calculated by the field model. The zone model approximation assumes that the flow through the vent is a function of the hydrostatic pressure difference across the vent and a vent coefficient. The hydrostatic pressure in the zone model approximation will be a function of layer temperature and height within the layer. Since the layer temperature is assumed to be a constant in the zone model, the pressure within a layer will vary linearly with height within the layer. Figure 12 gives a plot of the $x$ direction flow velocity versus flow velocity if only a hydrostatic head is used where the pressure beyond the door is assumed to remain at ambient. The layer height was obtained from the field modeling calculations of the two room experiment using the method proposed by Cooper [14] and the layer temperatures were then calculated by averaging the temperature in each layer. The shape of the inflow velocities as calculated by the zone model approximation compares favorably with the field model results. If the layer height had been fixed at a lower level, the comparison of the shapes would be excellent.

The deviation between the field model and zone model calculations at node 35 and above occurs because of presence of the door soffit which was included in the field model calculation but was ignored in the zone model calculation. The 


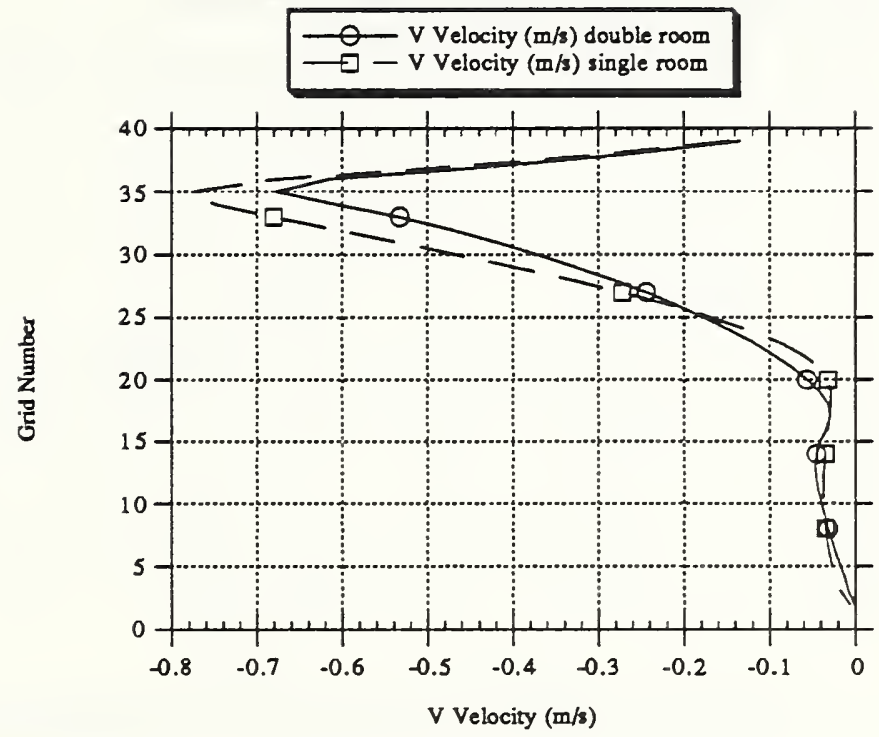

Figure 10: Vertical Vent Velocities at 200 Seconds

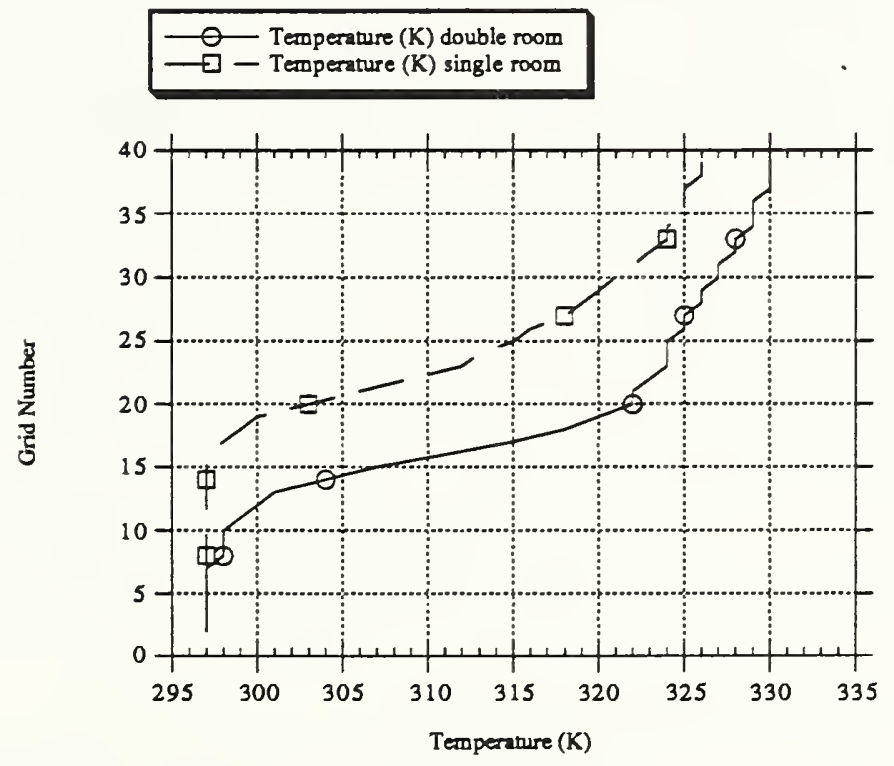

Figure 11: One and Two Room Temperature Profile in the Vent 


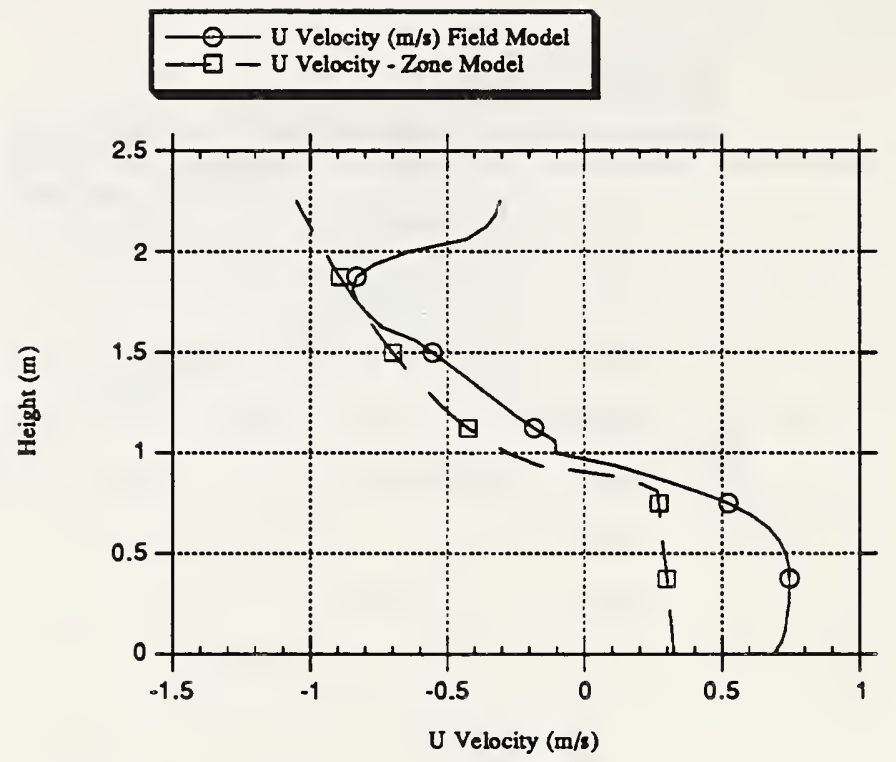

Figure 12: Horizontal Velocity Profiles in the Vent

soffit acts as a solid barrier thus rapidly reducing the $x$ or horizontal velocity flow for the field model calculation. The flow around the soffit also introduces a vertical component to the flow which is readily seen in figure 10 . The zone model approximation assumes that the flow velocities are only horizontal with no vertical component.

One of the major differences between the field model calculation and the zone model approximation is that the zone model gives the location of the maximum inflow velocity to be at the bottom of the door while the field model calculation shows that the maximum inflow velocity occurs above the bottom of the door. The reason for the difference is that the zone model only includes pressure differences to determine flow velocities while the field model includes not only pressure differences but also momentum and viscous effects.

A comparison of the predicted zone model temperature profile compared with the calculated two room temperature profile is shown in figure 13 . The zone model temperatures are deduced by finding an average temperature in each layer after the layer height has been calculated. Calculating the layer height properly is critical in determining whether the enthalpy flow out the vent will be successfully approximated by a zone model.

\subsection{Computational Accuracy}

A study of the effects of computational accuracy was performed for this case. To introduce the computational methods used in the field model, the conservation 


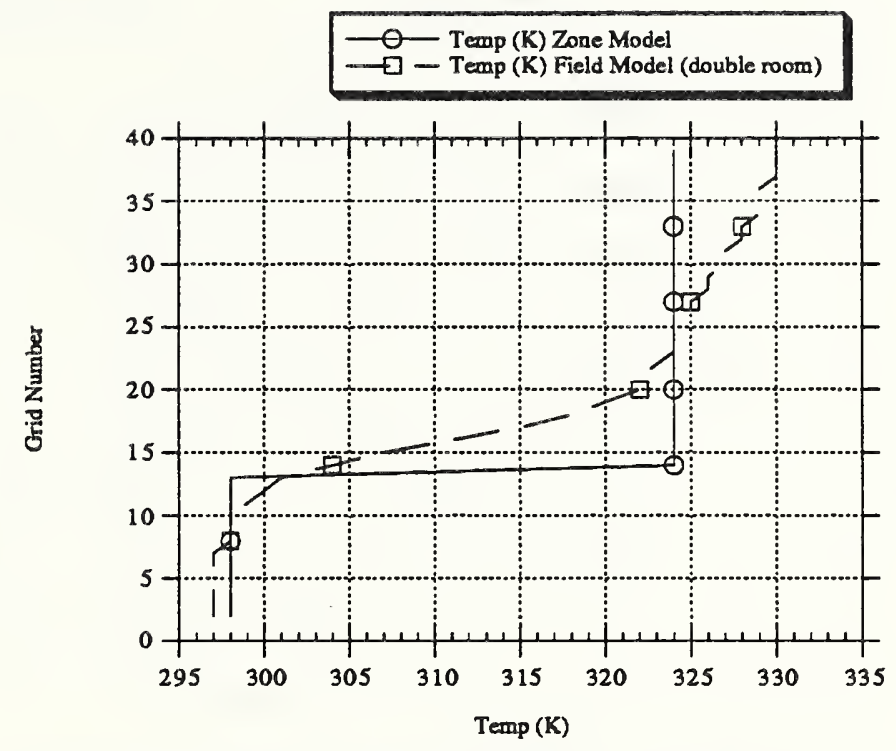

Figure 13: Zone and Field Model Temperature Profiles in the Vent

or Navier-Stokes equations are discretized to form a set of non-linear finite difference equations. This is done by replacing each differential operator with a finite difference analog. Central, backward, and up-wind difference formulas are three discretizations used by the field model. The problem then is to find at various times the mass, momentum (for each direction), enthalpy and if a $k-\epsilon$ turbulence model is used a turbulent kinetic energy and a turbulent dissipation rate that satisfies the non-linear difference equations for each control volume or node. This set of non-linear equations is solved iteratively by making a series of guesses. Each iteration of the non-linear problem is called an outer iteration. The non-linear difference equations are linearized. A linear system must then be solved for each solution variable, i.e. velocity, enthalpy etc. Again, an iterative procedure is used. Each iteration for these linear problems is called an inner iteration. Iterative methods are necessary for solving the outer non-linear difference equations and the inner linear systems due to the large number of equations that must be solved. Direct methods such as Gaussian elimination are not feasible except for trivially small problems.

The number of inner and outer iterations affect both the accuracy of the results and the amount of computer time required to obtain them. The residual mass at each time step is the sum of all the net mass flow between control volumes in the system. If there are no sources or sinks then the sum of all mass exchanges between control volumes must be zero. It is essential that the mass residual be sufficiently small to insure that the flow fields are modeled accurately. Figures 14, 15, and 16 show the relationships between the number 


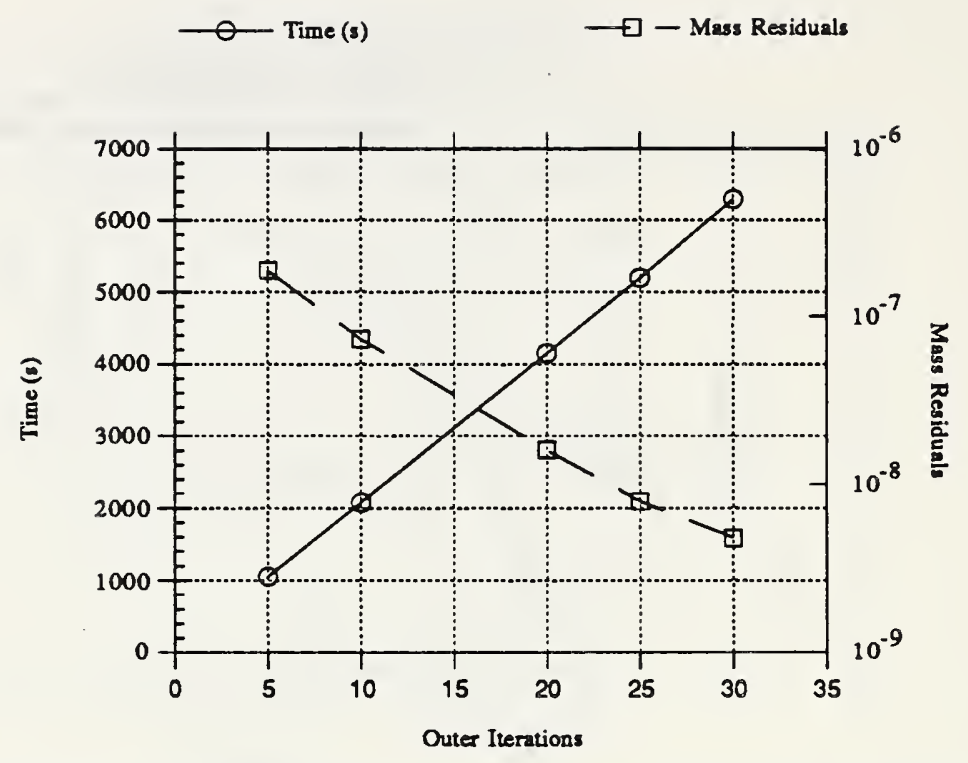

Figure 14: Inner Pressure Iteration Impact on Computer Time and Mass Residuals

of inner pressure iterations, number of outer iterations, timestep size, computer time or time to perform the calculation and the size of the mass residuals. There is a tradeoff between accuracy and efficiency.

Figure 14 shows the importance of solving the pressure equation accurately. Increasing the inner pressure iterations from 20 to 50 results in a three order of magnitude reduction in mass residuals. Figure 15 shows that as the number of outer iterations increases the mass residuals decrease and the computer time increases. Figure 16 illustrates the effect of time step size on computer time and mass residual size. As the time step size increases the residual size increases and the computer time decreases. The computer time required to solve the problem is inversely proportional to the time step size.

The computational experiments were performed on a Convex $\mathrm{C} 120$ and a Silicon Graphics Personal Iris model 4D35. Both computers used 32 bit or single precision arithmetic for these calculations. Though the architectures of these two computers are significantly different ${ }^{3}$ the computer times for cases run for this report were comparable (within 10 per cent). Typical 2 -d cases described in this report took about seven hours to run. The 3-d cases took an order of magnitude longer, about 100 hours. Much time was also required to set up the required input files and to analyze the output.

\footnotetext{
${ }^{3}$ The $\mathrm{C} 120$ has vectorizing hardware that exploits operations involving matrices, vectors, etc. The 4D35 has super-scalar hardware consisting of the MIPS 3000/3010 RISC (reduced instruction set chip) chip set running at $36 \mathrm{MHZ}$
} 


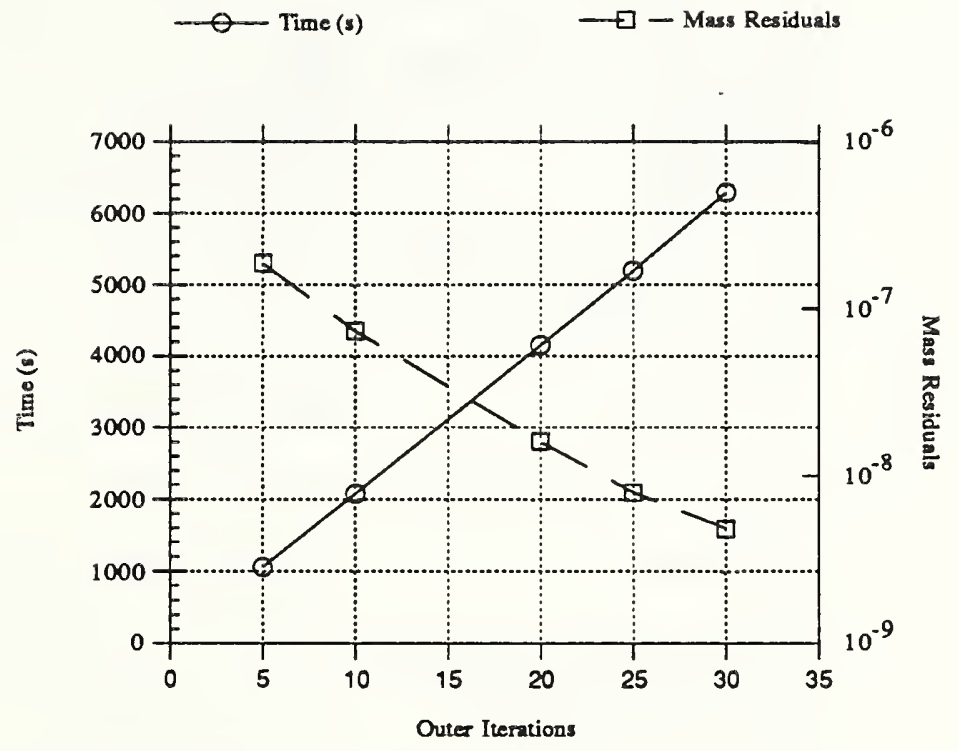

Figure 15: Outer Iteration Impact on Computer Time and Mass Residuals
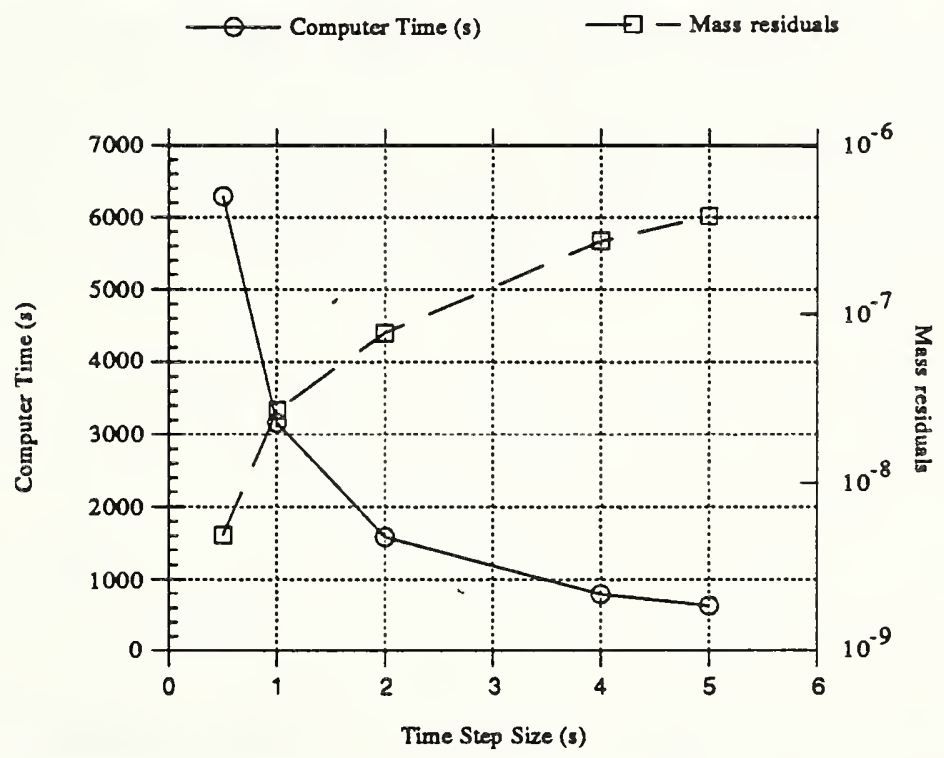

Figure 16: Time Step-Size Impact on Computer Time and Mass Residuals 
Table 2: Room Dimensions for the Three-Room Experiment

\begin{tabular}{ll}
\hline Location & Dimension $(\mathrm{m})$ \\
\hline First room & $2.34 \mathrm{~W} \times 2.34 \mathrm{~L} \times 2.16 \mathrm{H}$ \\
First room stub corridor & $1.02 \mathrm{~W} \times 1.03 \mathrm{~L} \times 2.00 \mathrm{H}$ \\
First room doorway & $.81 \mathrm{~W} \times 1.6 \mathrm{H}$ \\
Second room & $2.44 \mathrm{~W} \times 12.19 \mathrm{~L} \times 2.44 \mathrm{H}$ \\
Second room exit doorway & $.76 \mathrm{~W} \times 2.03 \mathrm{H}$ \\
Third Room & $2.24 \mathrm{~W} \times 2.22 \mathrm{~L} \times 2.43 \mathrm{H}$ \\
Third room stub corridor & $.79 \mathrm{~W} \times .94 \mathrm{~L} \times 2.04 \mathrm{H}$ \\
Third room doorway & $.79 \mathrm{~W} \times 2.04 \mathrm{H}$ \\
\hline
\end{tabular}

\section{Three Room Experiment}

\subsection{Experimental and Field Model Setup}

A set of experiments using a three room configuration [4] was chosen to test the three dimensional capabilities of the field model. This particular set of experiments used a burner as a fire source and therefore represented a much more controlled experimental environment than the single room test case. Of the nine sets of data available from the experiment, set four was chosen based on the quality of the data. The room geometry is shown in figure 17 with the room dimensions given in table 2.

Basically, the fire room, room one, is connected to a long second room or corridor through a short corridor with a door. There is a door at the far end of the second room and a third room connects to the second room by a short corridor near the far end of the second room.

A set of eight thermocouple trees was used to measure the temperature at various locations in the three rooms. These trees are depicted by crosses inside circles in figure 17. The locations, spacing and numbers of thermocouples on each tree are given in table 3 of reference 3 . For this report, five of the eight thermocouple trees are used to compare the experimental results with the numerical calculation.

The choice of grid was dictated by the detail of the structure to be modeled. The corridors and rooms had different ceiling heights and the door heights were 


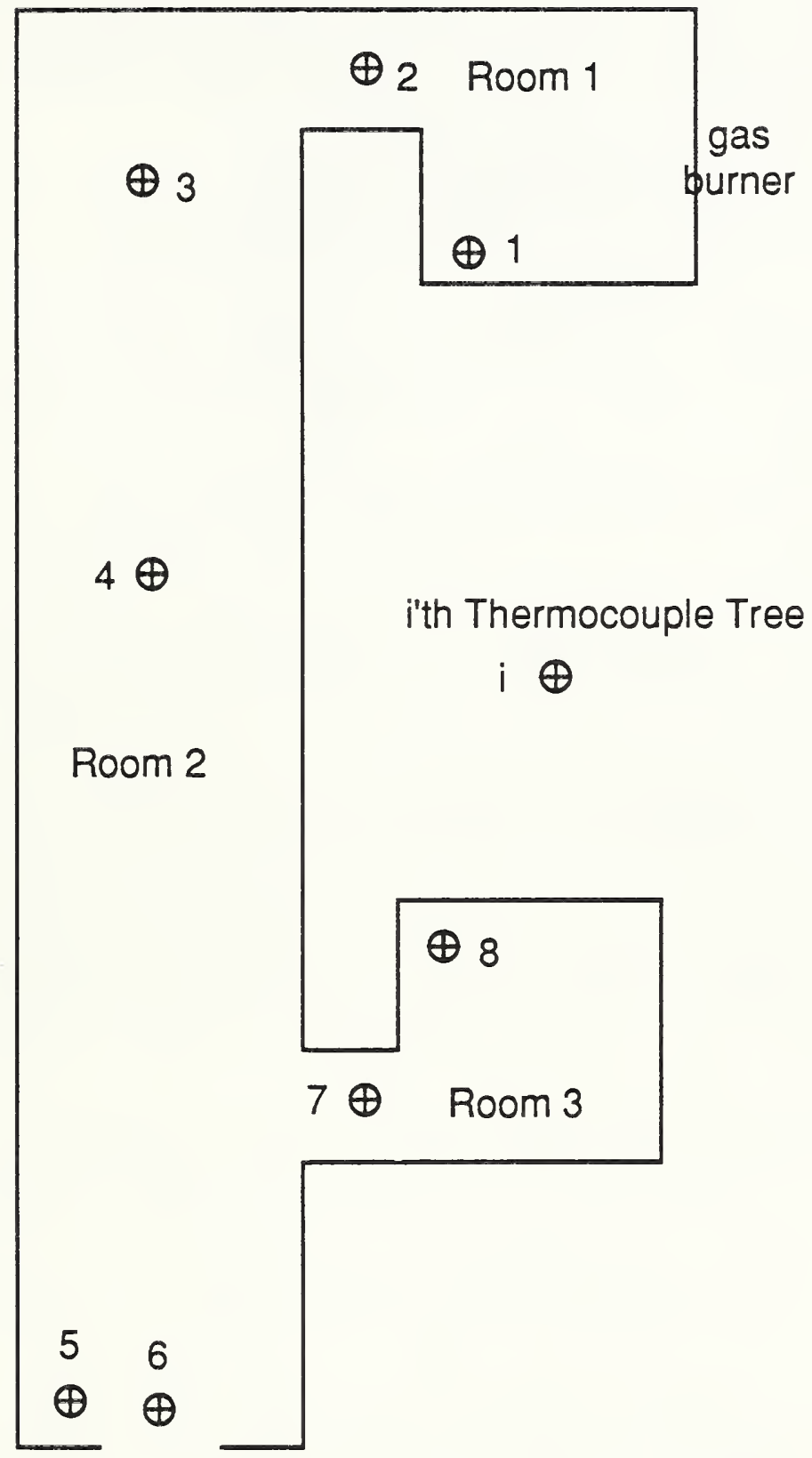

Figure 17: Three Room Experimental Layout and Thermocouple Configuration 
less than the ceiling heights. To keep a reasonable number of node points, it was decided that a grid of $32 \times 16 \times 14=7168$ cells with the $z$ direction being vertical would be used. This grid provided a spatial resolution of $4 \mathrm{~m}$ in the $x$ and $y$ directions and $.2 \mathrm{~m}$ in the $z$ direction. Since the smallest change in vertical dimensions was $.2 \mathrm{~m}$, all the changes in height could be modeled using a uniform grid.

A diffusion flame burner, centered at the middle of the back wall of the first room was the fire source. The top side of the burner had a $.34 \times .34 \mathrm{~m}$ porous ceramic surface with a perimeter of $13 \mathrm{~mm}$ wide steel plate. The porous surface was positioned $.5 \mathrm{~m}$ above the floor. A $2.8 \mathrm{~kW}$ pilot flame was attached to the front of the burner. The gas used was a mix of natural gas and acetylene in a $77 \mathrm{~kW}$ to $23 \mathrm{~kW}$ ratio respectively. The pilot flame was ignited first and burned for 300 seconds and then the main burner was turned on at a rate of $100 \mathrm{~kW}$ for data set 4 . The burner was allowed to burn at a constant rate for the next 900 seconds. The fire was modeled assuming that the heat released to the gas was $65 \%$ of the heat release rate with the remaining $35 \%$ being radiated to the walls. Since the walls were assumed to be adiabatic in this case, the radiation flux was in effect removed from the calculation. The heat release position for the burner was positioned in a single grid which was adjacent to the center line and to the right when facing the burner from the fire room door. The slightly off center line position was necessary because an even number of grids were chosen for the fire room. The pilot flame was located at the same off center line position and was located in the grid adjacent to the floor. For both burners, it was assumed that the power output was a constant over the interval that the burner was on.

The experiment was first modeled by assuming that the walls were adiabatic and that the door at the end of the second room could be sensibly modeled by using the outlet boundary condition. Only the first 500 seconds $^{4}$ of the experiment was modeled. For times longer than 500 seconds, until the gas burner was turned off only small changes in temperature occurred as the experiment was approaching steady state.

A second calculation was made in order to include energy losses to the ceiling by making the ceiling conducting. This was done by adding two additional layers of grids to the vertical direction to represent the solid thereby extending the grid size to $32 \times 16 \times 16$. These solid grids had a spatial width of $0.1 \mathrm{~m}$, and hence the grid used for the calculation was no longer uniform. It should be noted that the grids used to model the ceiling were much thicker than the actual wall material thus providing the ceiling with much greater thermal inertia than in the original experiment. The effect of this approximation means that more heat is lost to the ceiling than was originally experienced in the experiment. This effect is somewhat offset by the fact that the walls are still considered adiabatic in the calculation. A numerical instability was encountered when using very small grids to model the ceiling. Further work needs to be done in order to

${ }^{4} 300$ seconds of pilot burner and 200 seconds of the main burner 


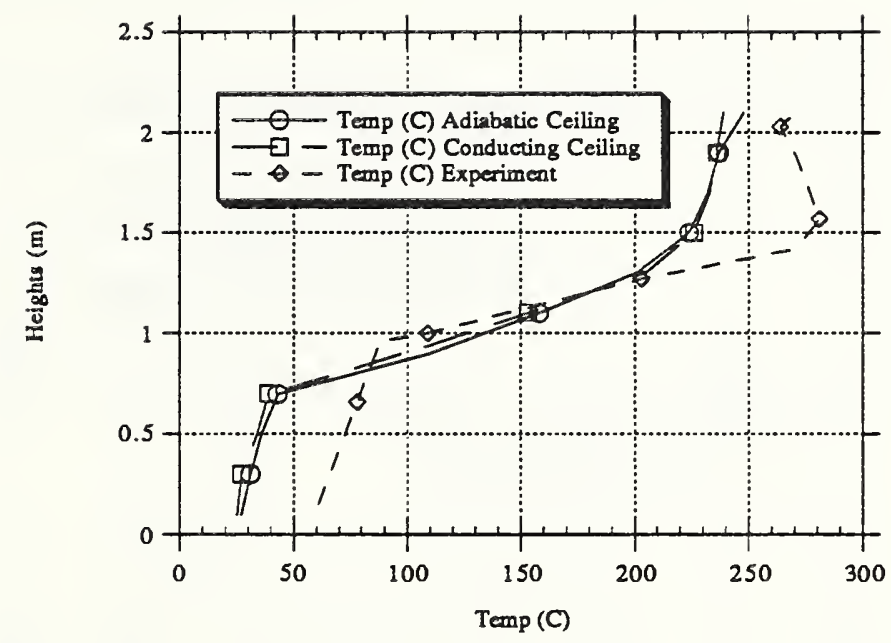

Figure 18: Temperature Profiles for Thermocouple Tree 1 at 500 Seconds

properly model situations that require substantial changes in grid size.

\subsection{Comparison of Experimental and Numerical Results}

Figures 18 through 22 give the temperature profile of the five thermocouple trees versus the calculated temperature profiles using an adiabatic and conducting ceiling at 500 seconds. Both ceiling types seem to give reasonable temperature comparisons with the thermocouple trees in the fire room, the connecting corridor and the first thermocouple tree in the second room nearest the fire room. The gas temperatures in the fire room both near the floor and near the ceiling are underestimated in the calculation. This is due to the lack of radiative heating of the ceiling, walls, and floor. In particular, if the floor were heated by radiation, the inflowing gas would be warmed by the floor yielding higher gas temperatures near the floor. There should also be a similar increase in gas temperature near the ceiling due to radiation heating of the walls and ceiling.

For the thermocouple trees at the far end of room two and in the corner of room three (tree 5 and tree 8 ), the calculation overestimates the temperature of the gas. Part of the reason for overestimating the temperature would come from the absence of heat loss to the walls. The effect of allowing the ceiling to remove heat is clearly demonstrated by noting the decrease in gas temperature that occurred when the ceiling was made conducting rather than adiabatic as shown in figures 21 and 22 . It would be expected that additional improvement 


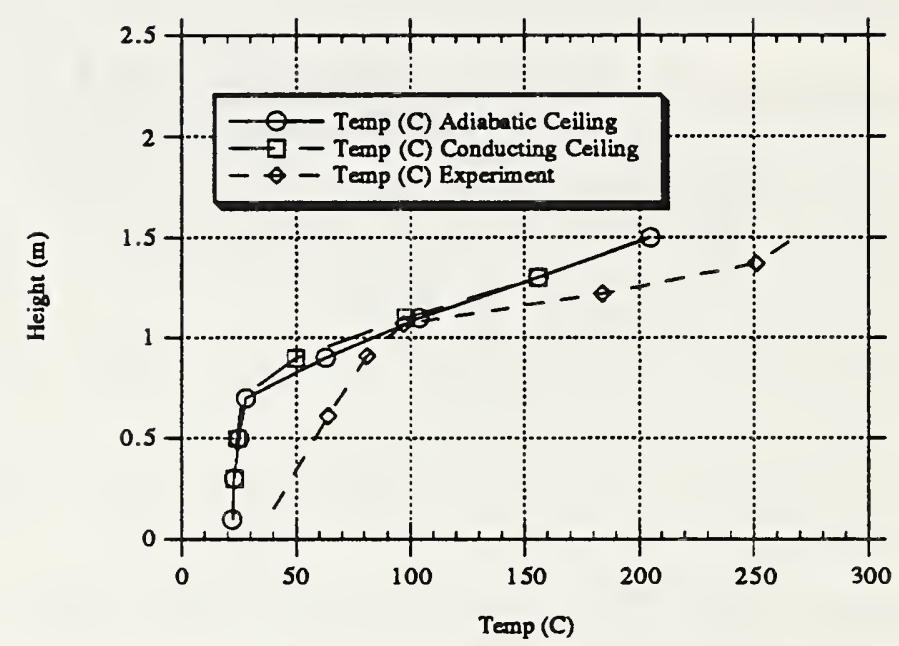

Figure 19: Temperature Profiles for Thermocouple Tree 2 at 500 Seconds

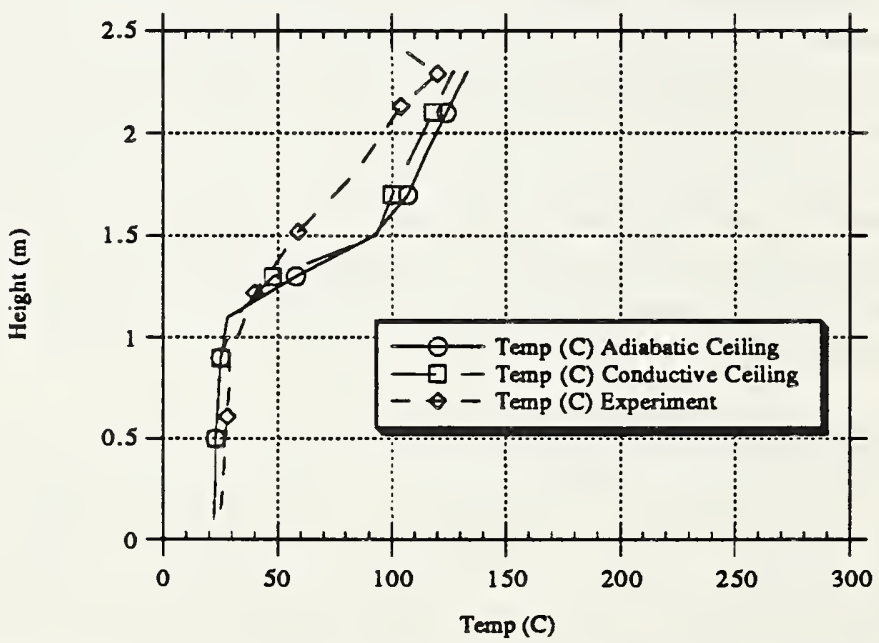

Figure 20: Temperature Profiles for Thermocouple Tree 3 at 500 Seconds 


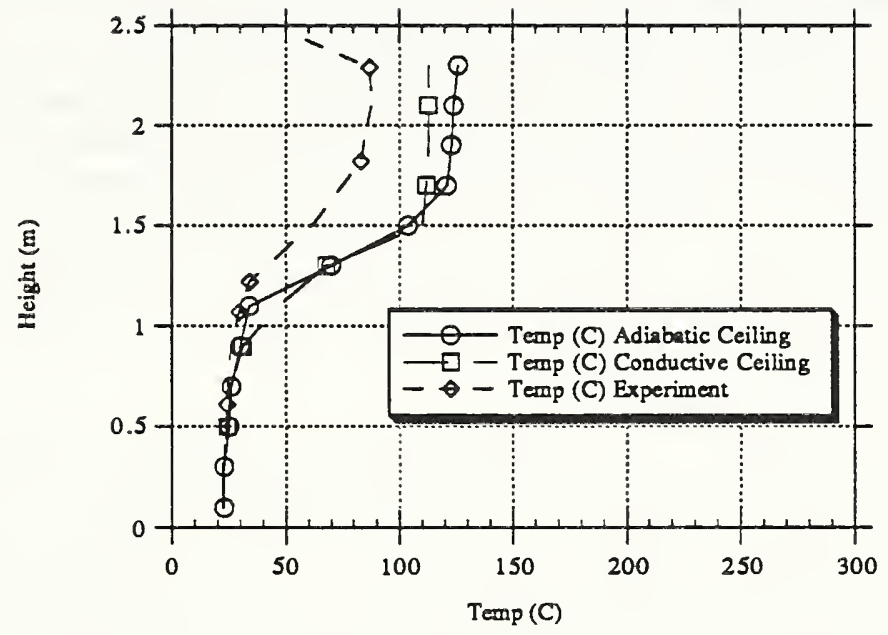

Figure 21: Temperature Profiles for Thermocouple Tree 5 at 500 Seconds

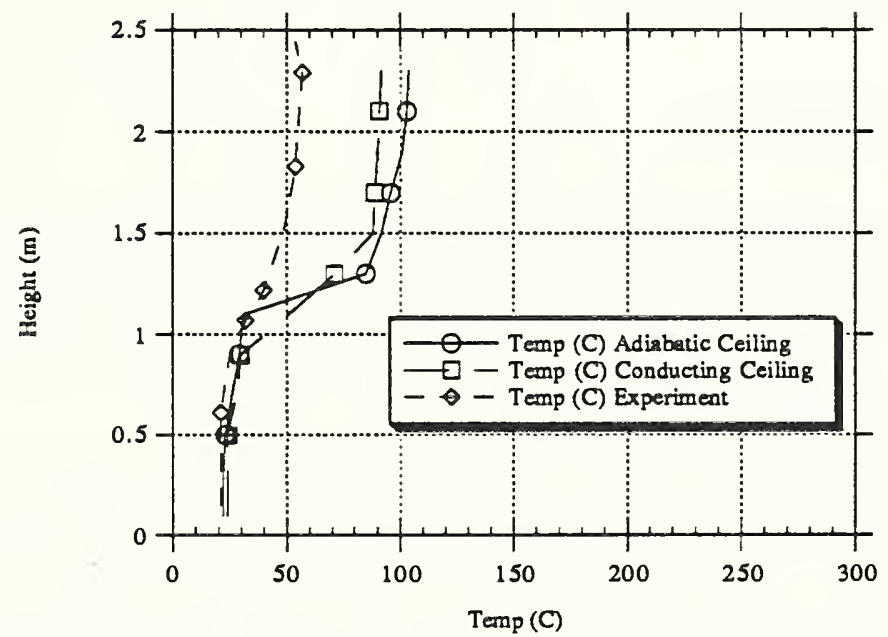

Figure 22: Temperature Profiles for Thermocouple Tree 8 at 500 Seconds 
in the agreement between the calculated and experimental temperatures would be realized by allowing the walls to be conducting. This modification was not tried due to the time constraints imposed on the project.

It should be noted that the exit door out of room two was modeled using the outlet boundary condition. From earlier discussion, one would expect this boundary condition to lower the local temperature since any heating of the inflowing air by the outflowing air is neglected. In this instance, however, the air temperatures are fairly low at the door and the door is relatively isolated from the rest of the experiment. It was felt therefore that during the first 200 seconds of the main burning phase of the experiment, modeling the door by the outlet boundary condition would only have a small impact on the overall calculations and the savings in computer time by minimizing the number of nodes would be substantial.

The impact on the calculation of varying the number nodes was only done in the vertical direction. Two calculations were performed. The first calculation used eight nodes to represent the vertical height. A second calculation which is reported in detail in this report used 14 nodes to represent the vertical height. While the additional detail provided by the 14 node calculation was valuable in comparing the experimental measurements with the calculation, the overall flow patterns and the values of the temperatures were approximately reproduced on the coarser grid.

The calculation must still be repeated with a doubling of nodes in the $X$ direction in order to verify that the flow in the corridors out of the fire room and into room three are begin simulated properly. Since each doubling of nodes in one of the dimensions increases the computation time by a factor of four, there is a practical limit to the number of nodes that can be used in a three dimensional calculation.

\section{Summary}

The simulation of the single room fire using FLOW3D was successful in that the measured temperatures for both the thermocouples and the simulated fusible links agreed closely with the calculated values. The absence of radiation in the calculations did not seem to effect the calculation of the ceiling jet interaction with the simulated fusible links.

The simulation of the three room experiment was not quite as successful in that even though the fire room was fairly well modeled, the temperature predictions for the third room and also for the far end of the second room were not as good. One reason for the poorer simulation of these areas far from the fire could be the use of too few nodes in modeling the flow through the doors and down the short corridors. A second reason could be the absence of heat convection to the walls since both thermocouple trees where the temperature was significantly overestimated were quite far from the fire and the dominant 
loss of energy in these areas would be by convection to the ceiling and walls.

Additional effort should be placed in simulating the three room experiment The simulation needs to be repeated with more nodes defining the door widths in the connecting corridors and also in the region of the plume. The effect of radiation needs to be included and the walls should be treated as conducting surfaces such that convective losses to the walls would be included in the calculation. If a significant difference between the results of the simulation and the experimental measurements persist, it would then be necessary to reexamine the experiment for some feature that is not being properly modeled and also examine the $k-\epsilon$ turbulence model and the convective heat transfer calculations to the walls and ceiling. 


\section{References}

[1] CFD Department, AEA Industrial Technology, Harwell Laboratory, Oxfordshire, United Kingdom. HARWELL-FLOW3D Release 2.3: User Manual, July 1990 .

[2] S. Simcox, N. S. Wilkes, and I. P. Jones. Computer simulation of the flows of hot gases from the fire at king's cross underground station. In Institution of Mechanical Engineers (IMechE) King's Cross Underground Fire: Fire Dynamics and the Organization of Safety, pages 19-25, London, England, 1989.

[3] Leonard Y. Cooper and David W. Stroup. Test results and predictions for the response of near-ceiling sprinkler links in a full-scale compartment fire. In T. Wakumatsu et al., editors, Fire Safety Science - Proceedings of the Second International symposium, Tokyo, June 13-17, pages 623-632, New York, 1988. International Association of Fire Safety Science, Hemisphere Publishing Co.

[4] Richard D. Peacock, Sanford Davis, and Billy T. Lee. An experimental data set for the accuracy assessment of room fire models. NBSIR 3752 , National Bureau of Standards, 1988.

[5] Walter W. Jones. A model for the transport of fire, smoke, and toxic gases. NBSIR 2937, National Bureau of Standards, 1984.

[6] E. E. Zukoski and Toshi Kubota. Two-layer modeling of smoke movement in building fires. Fire and Materials, 4:17-27, 1980.

[7] Henri E. Mitler and John A. Rockett. User's guide to first, a comprehensive single-room fire model. Internal Report 3595, National Institute of Standards and Technology, 1987.

[8] William D. Davis and Leonard. Y. Cooper. Estimating the environment and the response of sprinkler links in compartment fires with draft curtains and fusible link-actuated ceiling vents-part ii: User guide for the computer code lavent. Internal Report 4122, National Institute of Standards and Technology, 1989.

[9] William D. Walton. Private Communication.

[10] William D. Davis and Leonard Y. Cooper. A study of fusible link activation using a two dimensional ceiling jet model, lavent. To Be Published.

[11] National Fire Protection Association, Quincy Ma. Guide for Smoke and Heat Venting, NFPA $204 M, 1982$. 
[12] G. Heskestad and H. F. Smith. Investigation of a new sprinkler sensitivity approval test: The plunge test. Technical Report Serial No. 22485 2937, Factory Mutual Research Corporation, Norwood, MA, 1976. RC 76-T-50.

[13] Leonard. Y. Cooper. Estimating the environment and the response of sprinkler links in compartment fires with draft curtains and fusible link-actuated ceiling vents-part i: Theory. Internal Report 3734, National Institute of Standards and Technology, 1988.

[14] L. Y. Cooper, M. Harkleroad, J. G. Quintiere, and W. Rinkinen. Study of upper hot layer stratification in full-scale multiroom fire scenarios. J. Heat Trans., 104:741-749, November 1982. 


\section{A Field Model Command Files}

A listing of the command or input files necessary to run field model, FLOW3D and the graphics package, OUTPROC, are given below. Descriptions of each command in these files may be found in the user's manuals[1].

\section{A.1 One-Room Command Files}

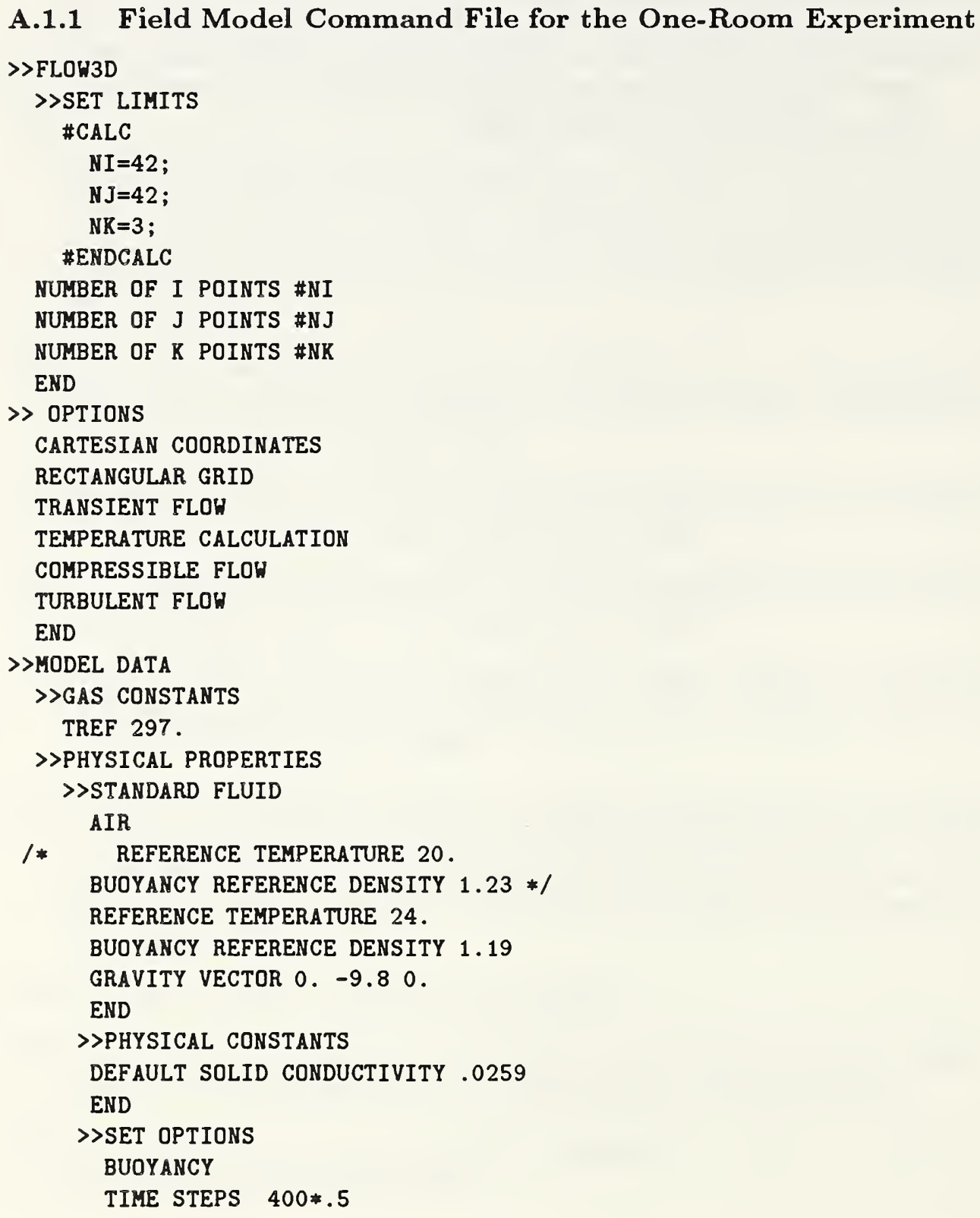




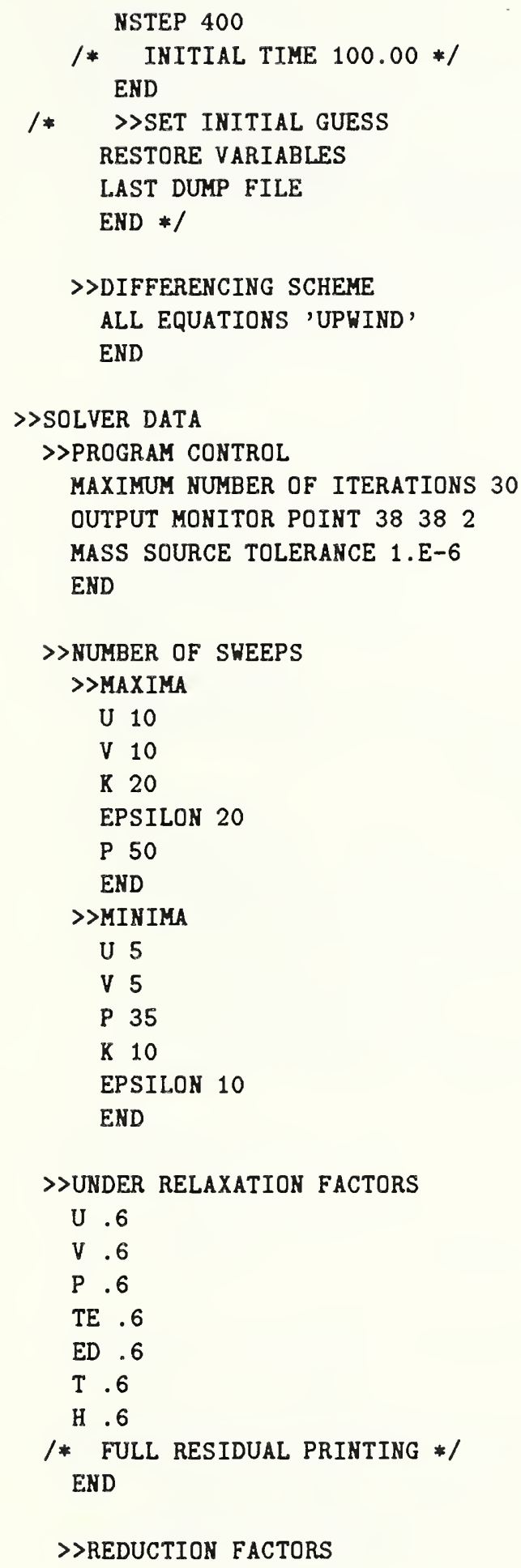




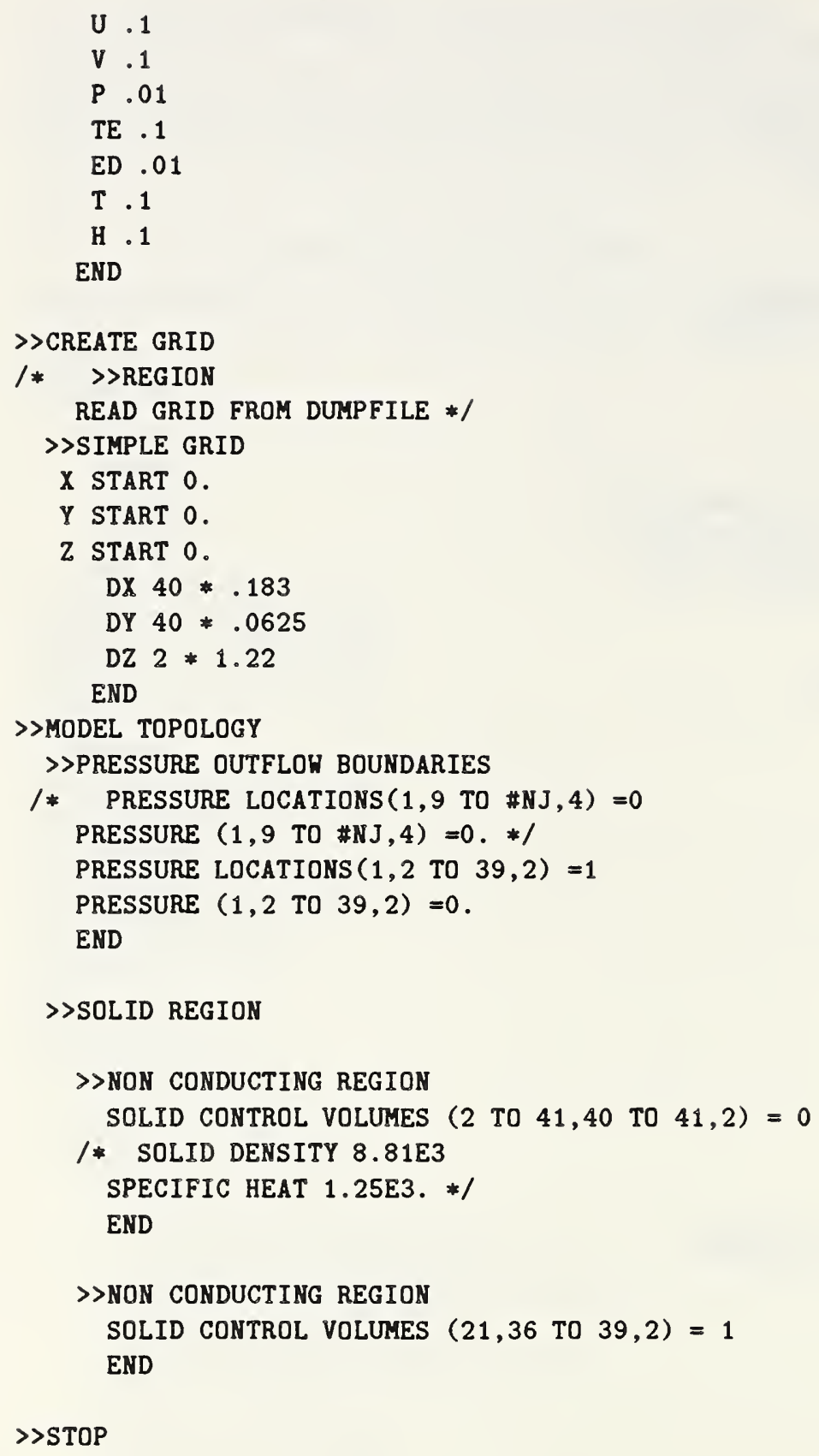

A.1.2 OUTPROC Command File for the One-Room Experiment $/ * * * * * * * * * * * * * * * * * * * * * * * * * * * * * * * * * * * * * * * * * * * * * * * * * * * * * * * * * * * * * /$
$/ * \operatorname{EXAMPLE~} 1:(\operatorname{EX1} 1 . \mathrm{OCMD})$
$/ * * * * * * * * * * * * * * * * * * * * * * * * * * * * * * * * * * * * * * * * * * * * * * * * * * * * * * * * * *) /$ 


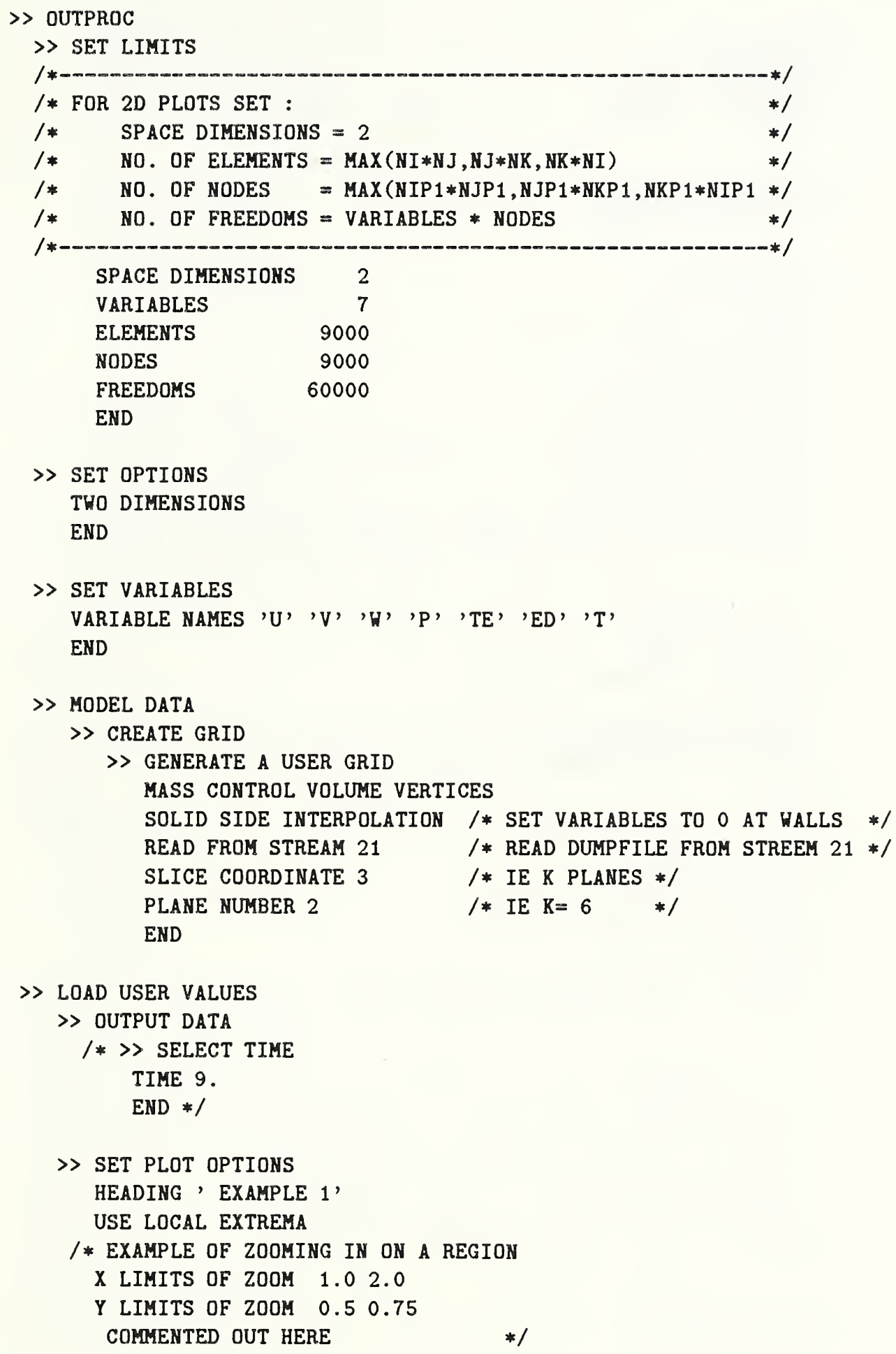




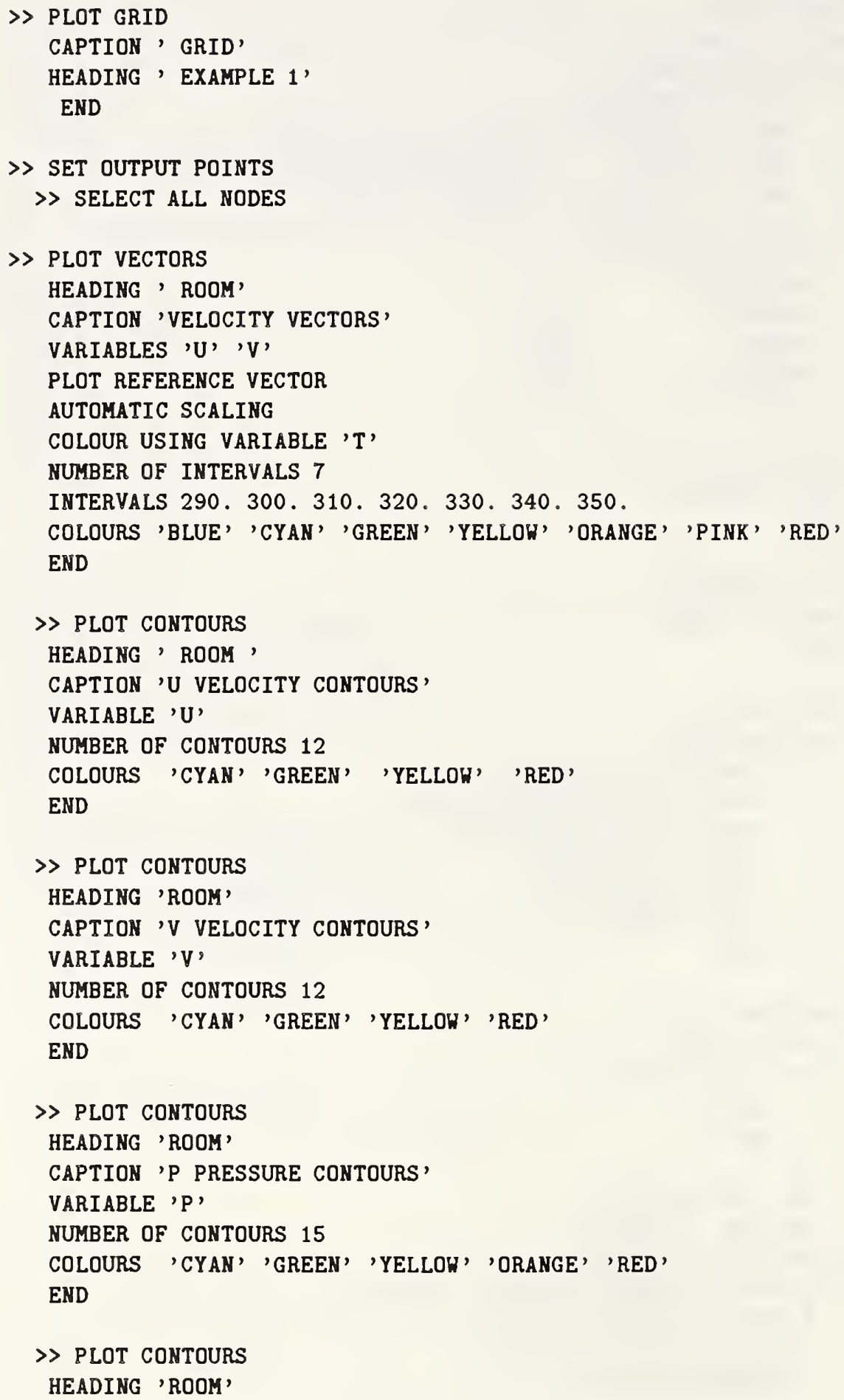




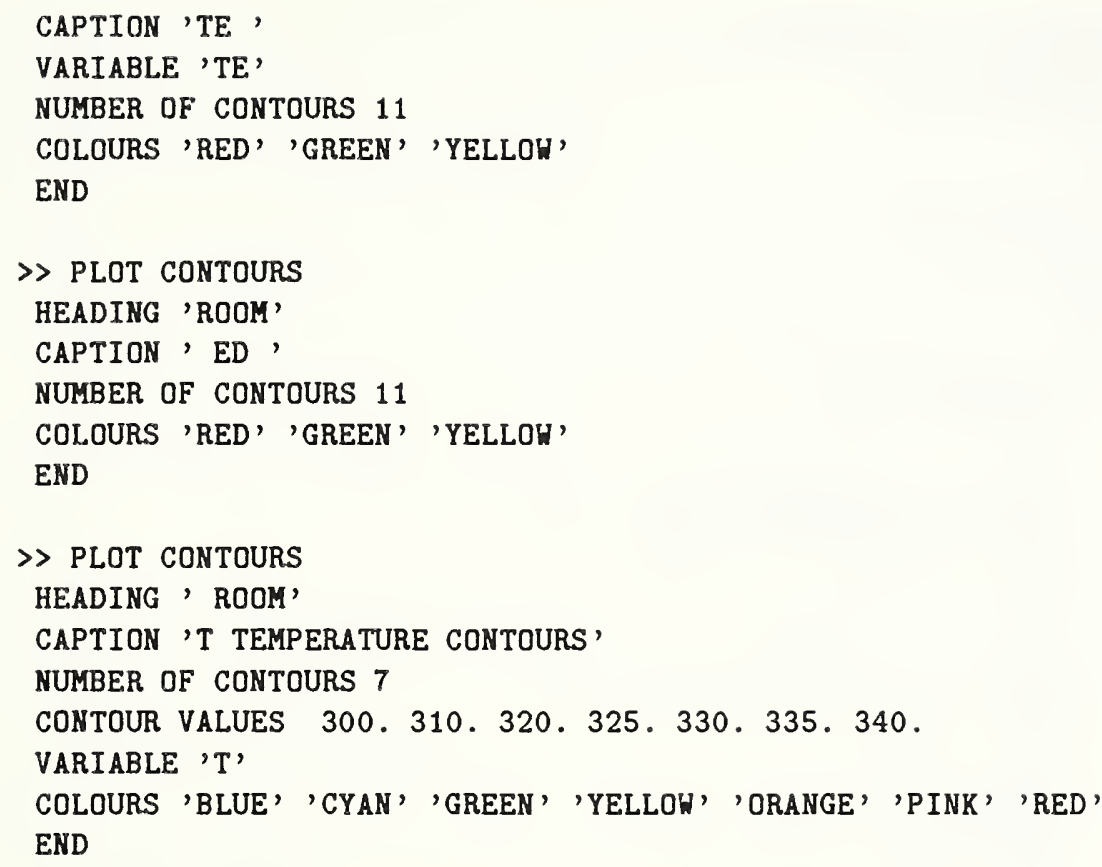

\section{A.2 Three-Room Field Model Command File}

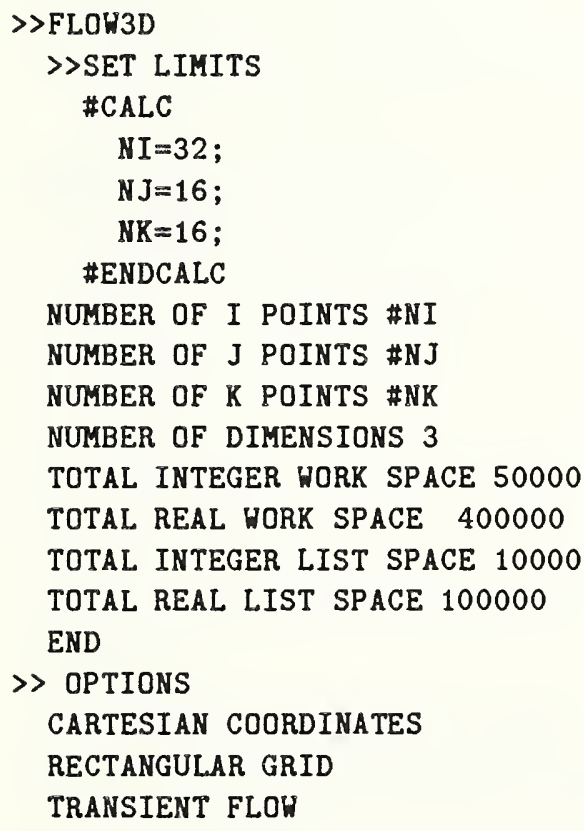




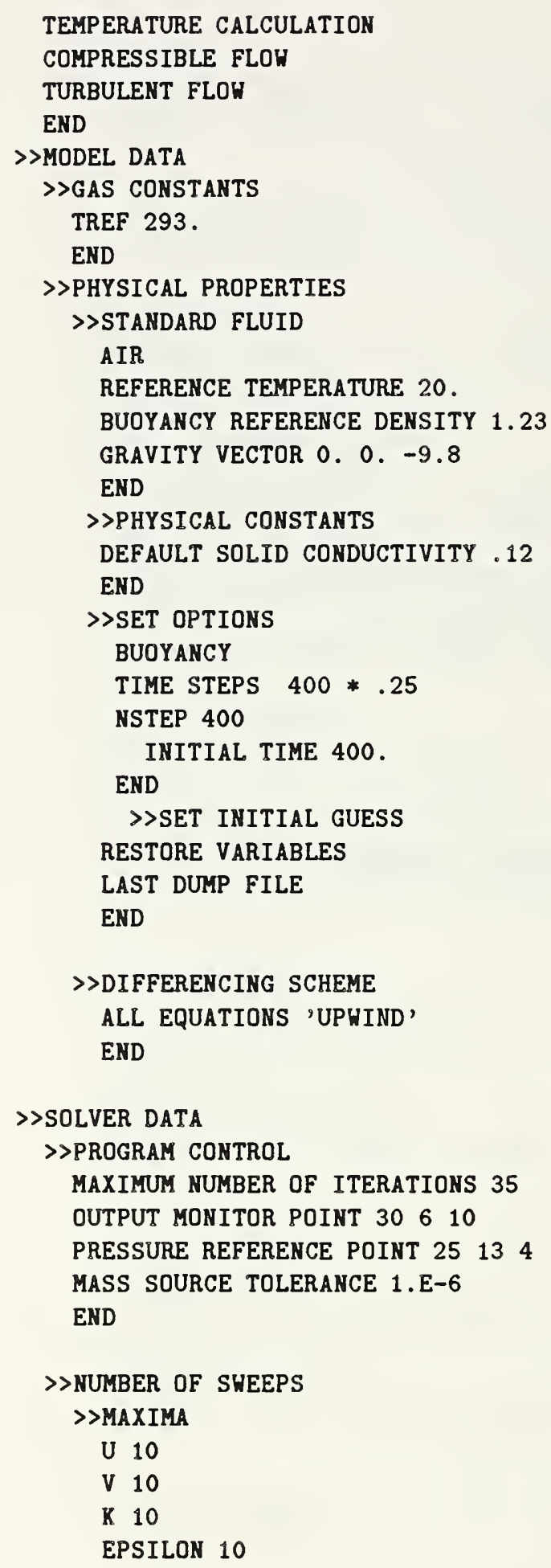




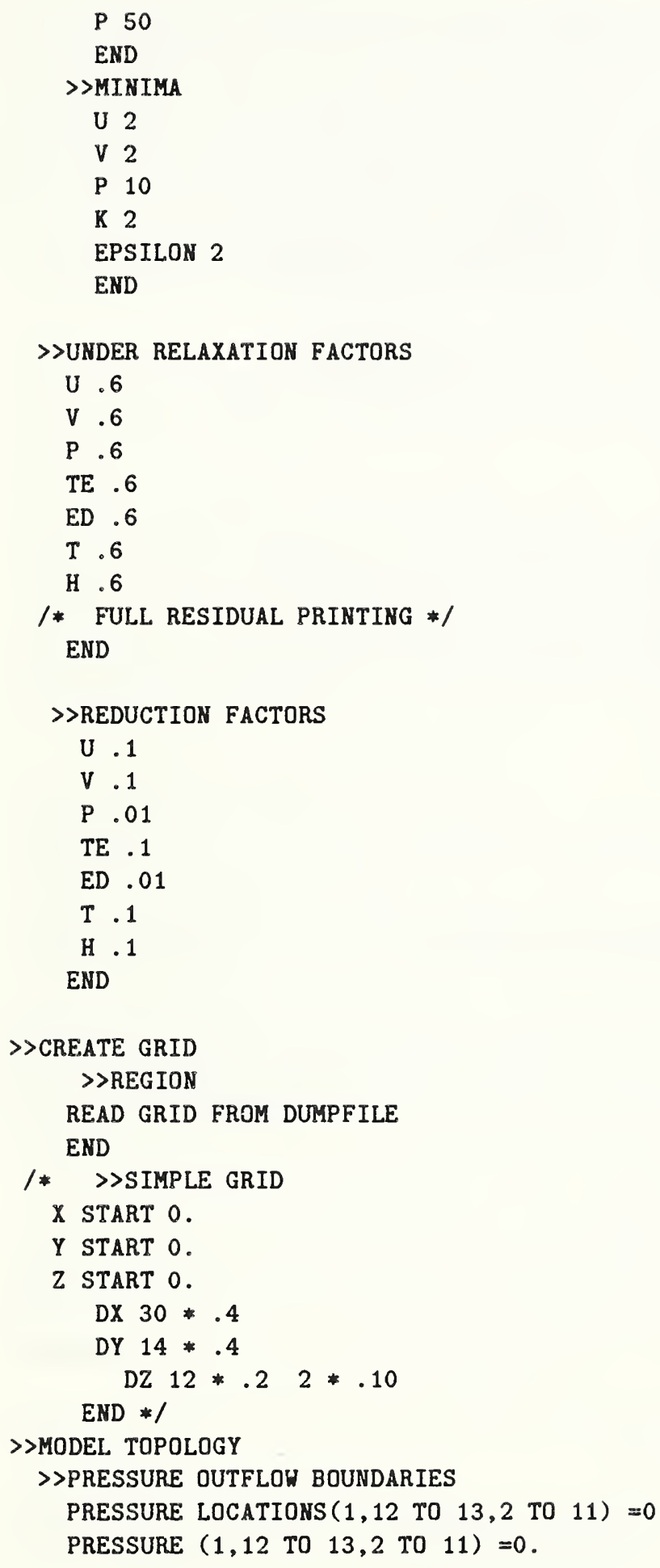




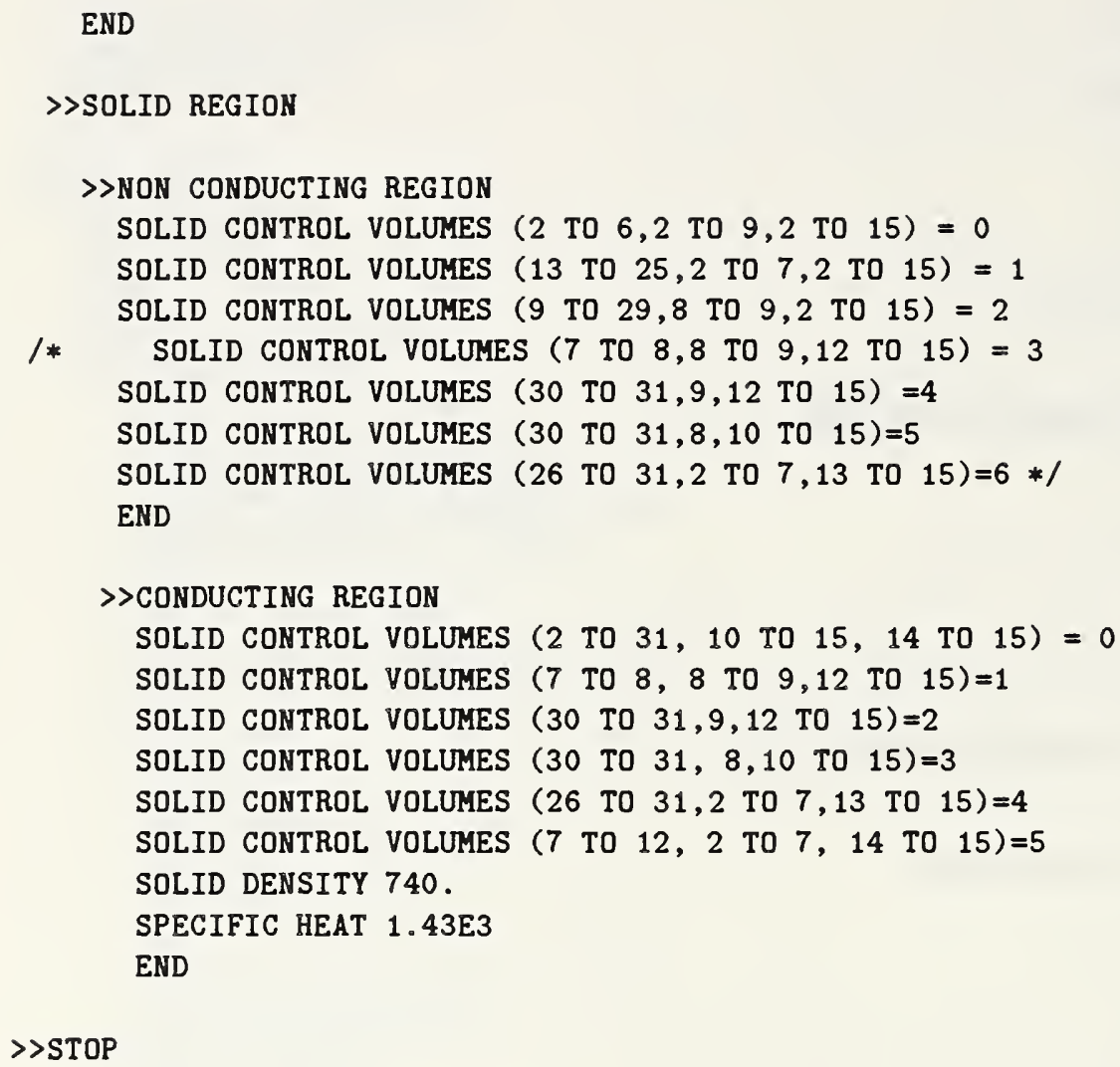

\section{B Field Model Subroutines}

The following set of subroutines are used in the simulation of the experiments described in this report. The subroutines are grouped by application and will not be described in detail as adequate documentation exists in the code for each subroutine.

\section{B.1 TRAN Subroutines}

Two subroutines are used to build the data files used by the graphics program TRAN. These subroutines are USRPLT and EXTPLT. The number of variables that may be output at present are four and are chosen by specific inputs in USRPLT.

\section{B.2 Outlet Subroutines}

A series of six subroutines are used to modify the conditions at the outlets. From the standpoint of fire modeling, if the default outlet calculation is used, 
the temperature of any inflowing gas through the outlet is taken to be equal to the temperature of the last adjacent grid before the outlet. With this set of subroutines, inflow temperature is changed to the reference temperature provided that the calculation is done using the compressible gas option. If the gas is treated as an incompressible gas, the inflow reference temperature will be 0 . These routines also allow other changes to be made to the boundary conditions but the ease of making the changes has not been explored. The set of subroutines are USRPRS, BCSTMP, CENTH, CSCALR, CT, and CTFN.

\section{B.3 Heat Source Subroutine}

Heat sources, both time dependent and time independent may be inserted into the subroutine USRSRC. This subroutine is called at every calculation cycle and provides access to all the program variables and the necessary parameters to control how the program variables are to be used. When inserting heat sources into the code, the most important problem to overcome is to make sure that the volume heat release rate is correct for the fire being modeled. Too large or too small of volume heat release rate will yield incorrect temperatures which will then have an effect on the buoyancy of the gas and the accuracy of the simulation.

\section{B.4 Fusible Link Subroutine}

The fusible link algorithm was entered in the subroutine USRTRN which is called at the end of each computed timestep. The entire set of program variables are available in this subroutine. Any computation which does not couple back into the main set of program variables can be performed as a side calculation in this subroutine.

\section{B.5 Machine Dependent Parameter Subroutine}

Subroutine USRMON was used by Harwell to correct an underflow error in the turbulent energy calculation that was uncovered when FLOW3D was used on the thirty-two bit workstation. Basically, certain variables are prevented from taking on values that are smaller than can be handled by these machines. This subroutine must be present when FLOW3D is run using turbulence.

\section{Boundary Conditions}

The boundary conditions at the outlet are treated by assuming that the flow is fully developed such that

$$
\frac{\partial \Phi}{\partial n}=n \cdot \nabla \Phi=0
$$


where $\Phi$ represents one of the variables such as velocity, turbulent energy, temperature, etc. For Cartesian geometry, the boundary condition is simply satisfied by copying the value of phi from the interior control volume adjacent to the outlet into the neighboring exterior control volumes. By using the outlet subroutines described in appendix B, the inflowing enthalpy or temperature may be set by the user to values other than the ones found in the neighboring control volumes. 


\begin{tabular}{|c|c|c|}
\hline \multirow[t]{4}{*}{$\begin{array}{l}\text { PIST-114A } \\
\text { (REV. 3-90) }\end{array}$} & \multirow[t]{2}{*}{$\begin{array}{l}\text { U.S. DEPARTMENT OF COMMERCE } \\
\text { NATIONAL INSTITUTE OF STANDARDS AND TECHNOLOGY }\end{array}$} & $\begin{array}{l}\text { 1. PUBLCATION OA REPORT NUMBEA } \\
\text { NISTIR } 4673\end{array}$ \\
\hline & & PERFORMING ORGANIZATION REPORT NUMBER \\
\hline & \multirow[t]{2}{*}{ BIBLIOGRAPHIC DATA SHEET } & 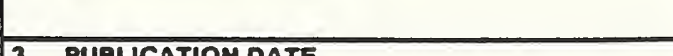 \\
\hline & & November 1991 \\
\hline
\end{tabular}

4. TITLE AND SUBTITLE

Field Modeling of Room Fires

5. AUTHOR(S)

William D. Davis, Glenn P. Formey and John H. Klote

\begin{tabular}{|l|l|}
\hline 6. PERFORMING ORGANIZATION (IF JOINT OR OTHER TMAN MIST, SEE INSTRUCTIONS) & 7. \\
U.S. DEPARTMENT OF COMMERCE \\
MATIONAL INSTITUTE OF STANDARDS AND TECHNOLOQY \\
GAITHERSBURG, MD 20899 & 8. TYPE OF REPORT AND PERIOD COVERED \\
\hline
\end{tabular}

9. SPONSORING ORGANIZATION NAME AND COMPLETE ADDRESS (STREET, CITY, STATE, ZIP)

10. SUPPLEMENTARY NOTES

11. ABSTRACT (A 200-WORD OR LESS FACTUAL SUMMARY OF MOST SIGNIFICANT INFOAMATION. IF DOCUMENTIMCLUDES A SIGNIFICANT BIBUOGRAPHY OR UTERATURE SURVEY, MENTION IT HERE,

The application of the Harwell field model, FLOW3D, to model compartment fires is investigated. Two experiments are chosen to model numerically. The first experiment is a single room fire where the vertical structure of the ceiling jet produced by the fire is measured and the temperature response of simulated fusible links to the ceiling jet is available. The second experiment consists of three rooms with a fire. Temperature measurements using thermocouples are available in each of the three rooms as well as in the corridors connecting the rooms. These two experiments provide an opportunity to investigate both two and three dimensional field modeling of fires. It is found that the numerical results using the field model are in reasonable agreement with the experimental data. FLOW3D has been enhanced by the addition of a simple fusible link algorithm previously used in the zone fire model LAVENT. This algorithm used in conjunction with the field model produces good agreement with the measured fusible link temperatures found in the single room experiment.

12. KEY WORDS (6 TO 12 ENTRIES; ALPHABETICAL ORDER; CAPITALZE ONLY PROPER NAMES; AND SEPARATE KEY WORDS BY SEMICOLONS)

compartment fires; computational fluid dynamics; field models; room fires; validation; zone models

\begin{tabular}{|c|c|c|}
\hline \multicolumn{2}{|c|}{ 13. AVAILABIUTY } & \multirow{2}{*}{$\begin{array}{l}\text { 14. MUMBER OF PRINTED PAGES } \\
45\end{array}$} \\
\hline $\mathrm{X}$ & UNUMITEO & \\
\hline & $\begin{array}{l}\text { ORDER FROM SUPERINTENDENT OF DOCUMENTS, U.S. GOVERNMENT PAINTINO OFFICE, } \\
\text { WASHINGTON, DC } 20402 .\end{array}$ & \multirow[t]{2}{*}{ 15. PRICE } \\
\hline $\mathrm{X}$ & ORDER FROM NATIONAL TECHNICAL INFORMATION SERVICE (NTIS), SPRINGFIELD, VA 22161. & \\
\hline
\end{tabular}



